Supporting Information

for

\title{
A Dimeric Hydride-Bridged Complex with Geometrically Distinct Iron Centers Giving Rise to an $S=3$ Ground State
}

Anne K. Hickey, Samuel M. Greer, Juan Valdez-Moreira, Sean A. Lutz, Maren Pink,

Jordan A. DeGayner, T. David Harris, Stephen Hill, Joshua Telser, and Jeremy M. Smith* 


\section{Contents}

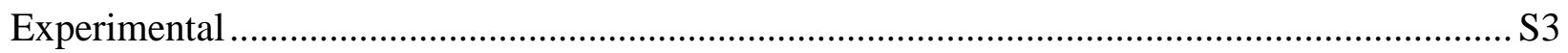

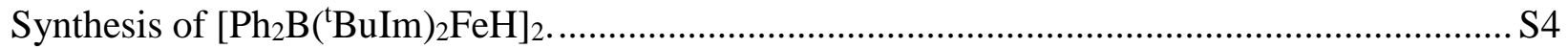

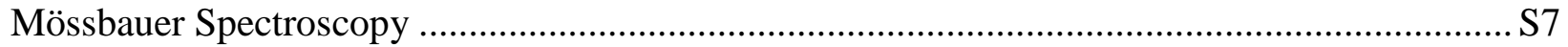

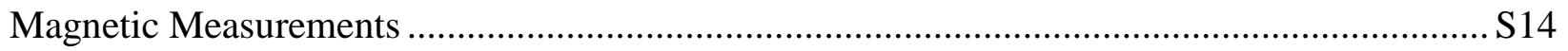

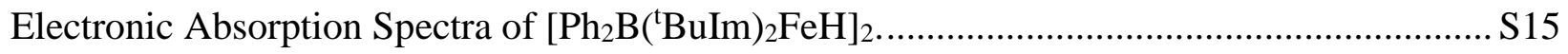

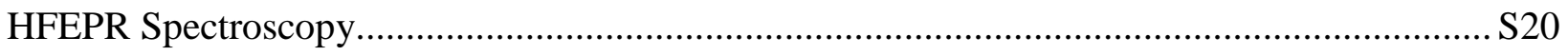

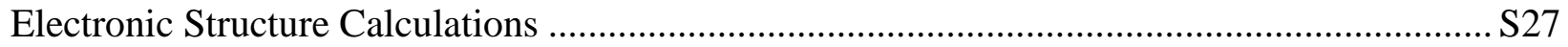

Molecular Orbital Analysis ............................................................................................. S32

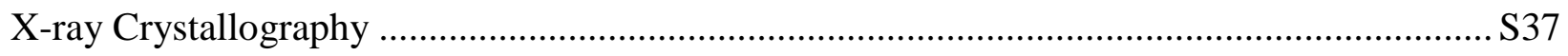

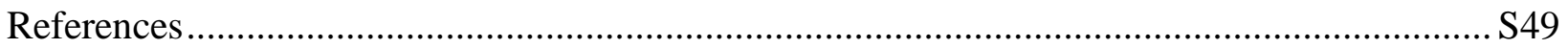




\section{Experimental}

General Considerations. All manipulations were performed under a nitrogen atmosphere by standard Schlenk techniques or in an MBraun glove box. Glassware was dried at $140{ }^{\circ} \mathrm{C}$ overnight before cooling under a dynamic vacuum in an antechamber. Diethyl ether $\left(\mathrm{Et}_{2} \mathrm{O}\right)$, tetrahydrofuran (THF), toluene, and pentane were purified by a Glass Contour solvent purification system. Celite was dried overnight at $130{ }^{\circ} \mathrm{C}$ under vacuum. The complex $\mathrm{Ph}_{2} \mathrm{~B}\left({ }^{t} \mathrm{BuIm}\right)_{2} \mathrm{FeCl}(\mathrm{THF})^{1}$ was prepared by literature methods. Sodium triethylborohydride 1.0 M THF solution was purchased from Sigma-Aldrich and used as received. Deuterated solvents were purchased from Cambridge isotope labs. $\mathrm{C}_{6} \mathrm{D}_{6}$ and THF- $d_{8}$ were degassed and stored over molecular sieves for at least one day before use. All other chemicals were purchased and used as received. ${ }^{1} \mathrm{H}$ NMR spectroscopic data were recorded on Varian $400 \mathrm{MHz}$ NMR spectrometers using J-Young tubes as sample holders. Solution magnetic susceptibilities were determined by Evans' method. ${ }^{2}$ UV-Vis spectroscopic data were collected on an Agilent Technologies Cary 60 UV-Vis instrument. IR spectra were recorded with a Perkin Elmer spectrophotometer. Mössbauer spectra were recorded on a SEE Co spectrometer. The sample temperature was controlled using a SVT-400 Dewar from Janis equipped with a Lake Shore 255 Temperature Controller. The isomer shifts are reported relative to the centroid of the spectrum of $\alpha-\mathrm{Fe}$ at $298 \mathrm{~K}$. Samples were prepared by grinding crystallized material into a fine powder and then mounting in a cup, plugged with a fitted O-ring sealed cap. Data analysis was performed using the program $\mathrm{WMOSS}^{3}$ and quadrupole doublets were fitted to Lorentzian lineshapes. Mass spectrometry measurements were made using an Agilent 1200 HPLC6130 MSD spectrometer. Elemental analysis was conducted by Midwest Microlab, LLC (Indianapolis, IN). 


\section{Synthesis of $\left[\mathrm{Ph}_{2} \mathrm{~B}\left({ }^{\mathrm{t}} \mathrm{BuIm}\right)_{2} \mathrm{FeH}\right]_{2}$.}

In a scintillation vial, $\mathrm{Ph}{ }_{2} \mathrm{~B}\left({ }^{\mathrm{t}} \mathrm{BuIm}\right)_{2} \mathrm{FeCl}(\mathrm{THF})(537 \mathrm{mg} 0.93 \mathrm{mmol})$ was dissolved in $\mathrm{THF}(3 \mathrm{~mL})$. Sodium triethylborohydride solution $(0.93 \mathrm{mmol}, 0.93 \mathrm{~mL}$ of $1.0 \mathrm{M})$ was added slowly to the vial. A color change to dark blue occurred immediately upon addition of the borohydride solution. The mixture was then stirred for $3 \mathrm{~h}$ at room temperature, the solvent was removed under vacuum, yielding a black solid. The solid was washed with pentane $(3 \times 3 \mathrm{~mL})$ to afford a dark blue solid (387 mg, 88\% yield). Crystals suitable for X-ray diffraction were grown from a concentrated THF solution layered with pentane and stored at $-35{ }^{\circ} \mathrm{C}$ overnight. ${ }^{1} \mathrm{H}$ NMR (THF- $\left.\mathrm{d}_{8}, 400 \mathrm{MHz}\right) \delta(\mathrm{ppm})$ 33, 18, 16, 7, 6, 2, 11, 19. Anal. Cald. for $\mathrm{C}_{52} \mathrm{H}_{66} \mathrm{~B}_{2} \mathrm{Fe}_{2} \mathrm{~N}_{8}$ : C 66.69, H 7.10, N 11.97; Found: C 66.67, $\mathrm{H}$ 7.31, $\mathrm{N}$ 11.64. The deuterated complex $\left[\mathrm{Ph} 2 \mathrm{~B}\left({ }^{\mathrm{B}} \mathrm{BuIm}\right)_{2} \mathrm{FeD}\right]_{2}$ was prepared analogously using $\mathrm{NaBEt}_{3} \mathrm{D}$ solution.

The variable temperature ${ }^{1} \mathrm{H}$ NMR spectrum is consistent with a high symmetry species in solution, suggesting a fluxional, dimeric structure on the NMR timescale (Figure S1). The linearity of the Curie-Weiss plot is consistent with the presence of a single paramagnetic species in solution over this temperature range (Figure S2). Isosbestic points are observed in the VT UV-vis spectrum, suggesting the presence of an equilibrium that is slow on the UV-vis timescale (Figure S3). However, these data provide no structural information on the nature of the equilibrium. 

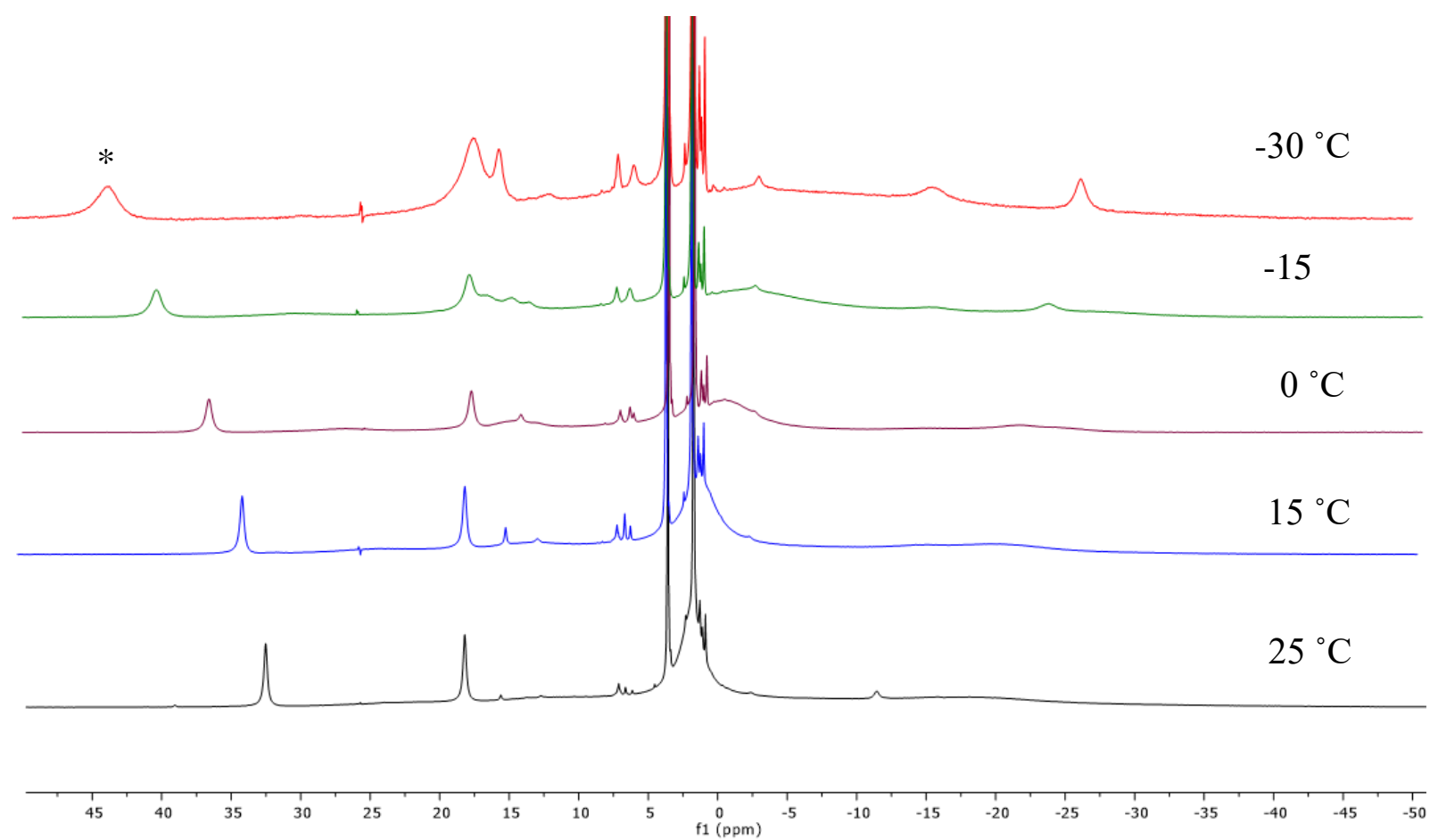

Figure S1. VT ${ }^{1} \mathrm{H}$ NMR spectra $\left(400 \mathrm{MHz}, \mathrm{THF}-\mathrm{d}_{8}\right)$ of $\left[\mathrm{Ph}_{2} \mathrm{~B}\left({ }^{\mathrm{t}} \mathrm{BuIm}\right)_{2} \mathrm{FeH}\right]_{2}$. The temperature dependence of the asterisked resonance was used to construct the Curie-Weiss plot in Figure S2. 


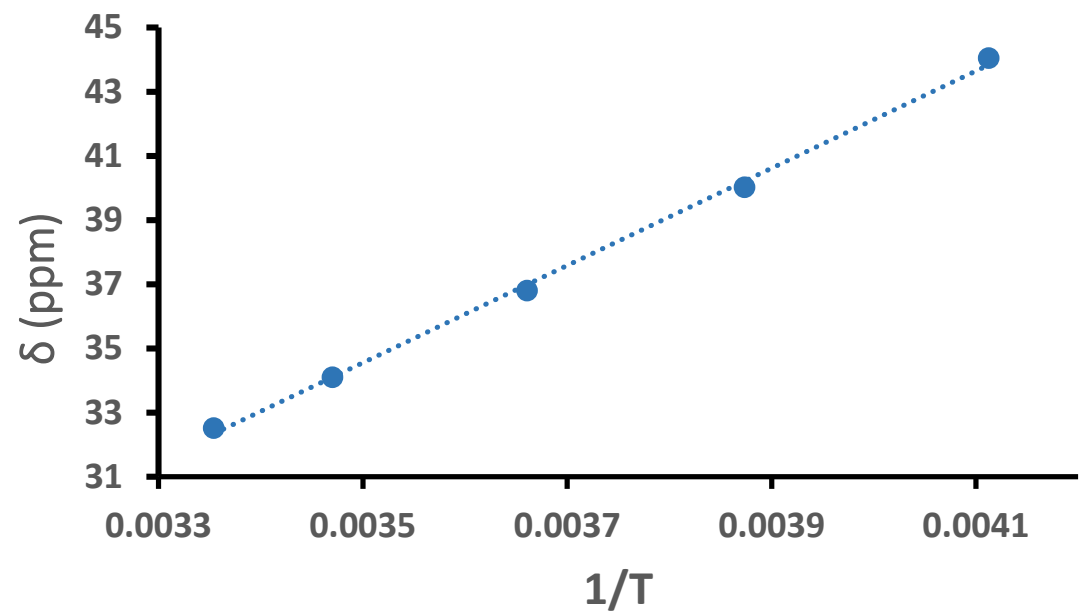

Figure S2. Curie-Weiss plot showing the linear relationship between chemical shift (ppm) and $1 / \mathrm{T}$.

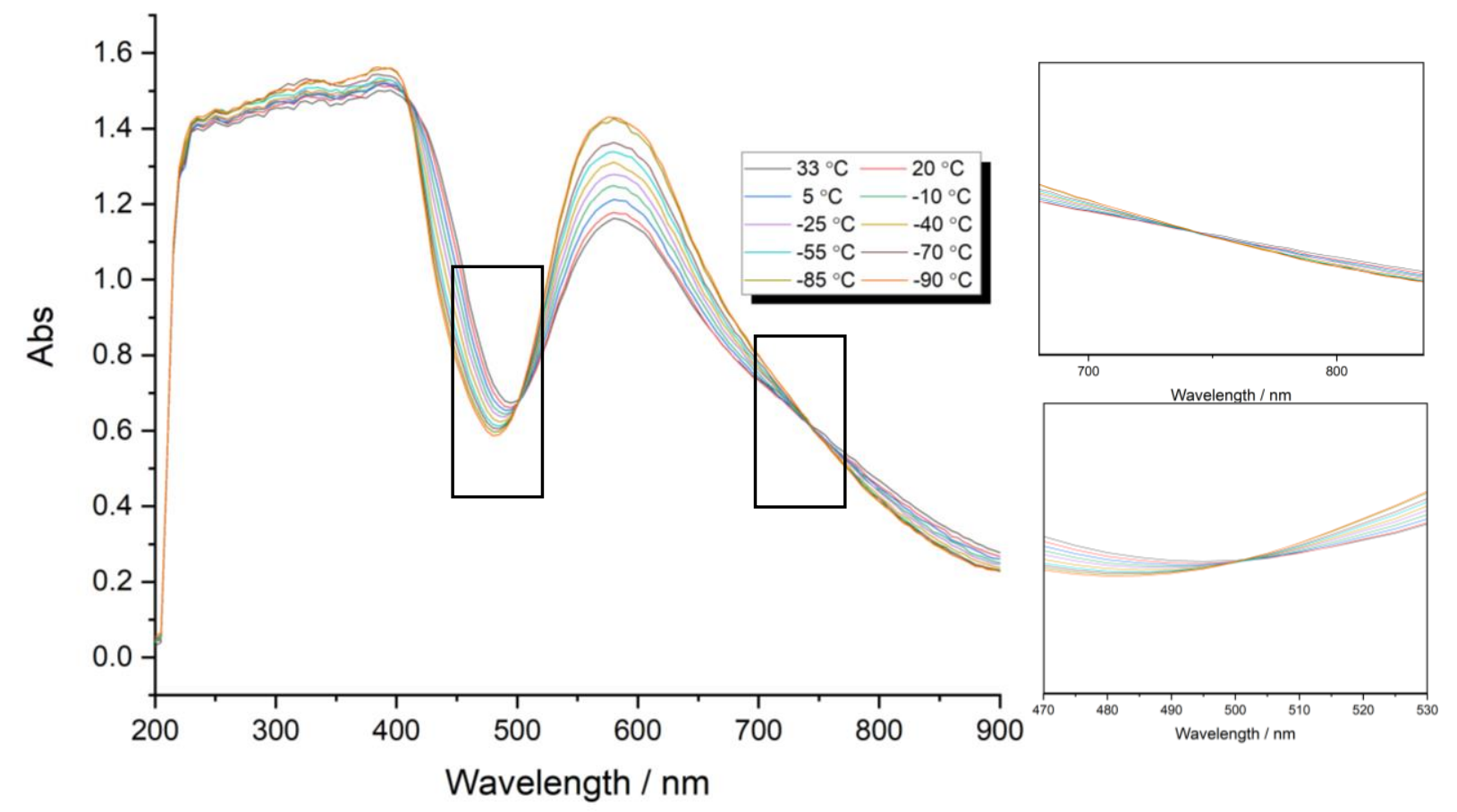

Figure S3. Variable-temperature UV-Vis spectra of $\left[\mathrm{Ph}{ }_{2} \mathrm{~B}\left({ }^{\mathrm{t}} \mathrm{BuIm}\right)_{2} \mathrm{FeH}\right]_{2}$ in THF, between 33 and $-90{ }^{\circ} \mathrm{C}$. Two isosbestic points are observed at 501 and $744 \mathrm{~nm}$. 


\section{Mössbauer Spectroscopy}

The Mössbauer spectrum of $\left[\mathrm{Ph}_{2} \mathrm{~B}\left({ }^{\mathrm{t}} \mathrm{BuIm}\right)_{2} \mathrm{FeH}\right]_{2}$ can also be fit to two different subspectra, with $\delta=-0.0432 \mathrm{~mm} / \mathrm{s}, \Delta E_{\mathrm{Q}}=2.993 \mathrm{~mm} / \mathrm{s}(60 \%)$, and $\delta=+0.881 \mathrm{~mm} / \mathrm{s}, \Delta E_{\mathrm{Q}}=2.672 \mathrm{~mm} / \mathrm{s}(40 \%)$ (Figure S4). This alternative fit gives isomer shift and quadrupole splitting values that are not reasonable, in light of Mössbauer parameters reported for related complexes (Tables S1-S7).

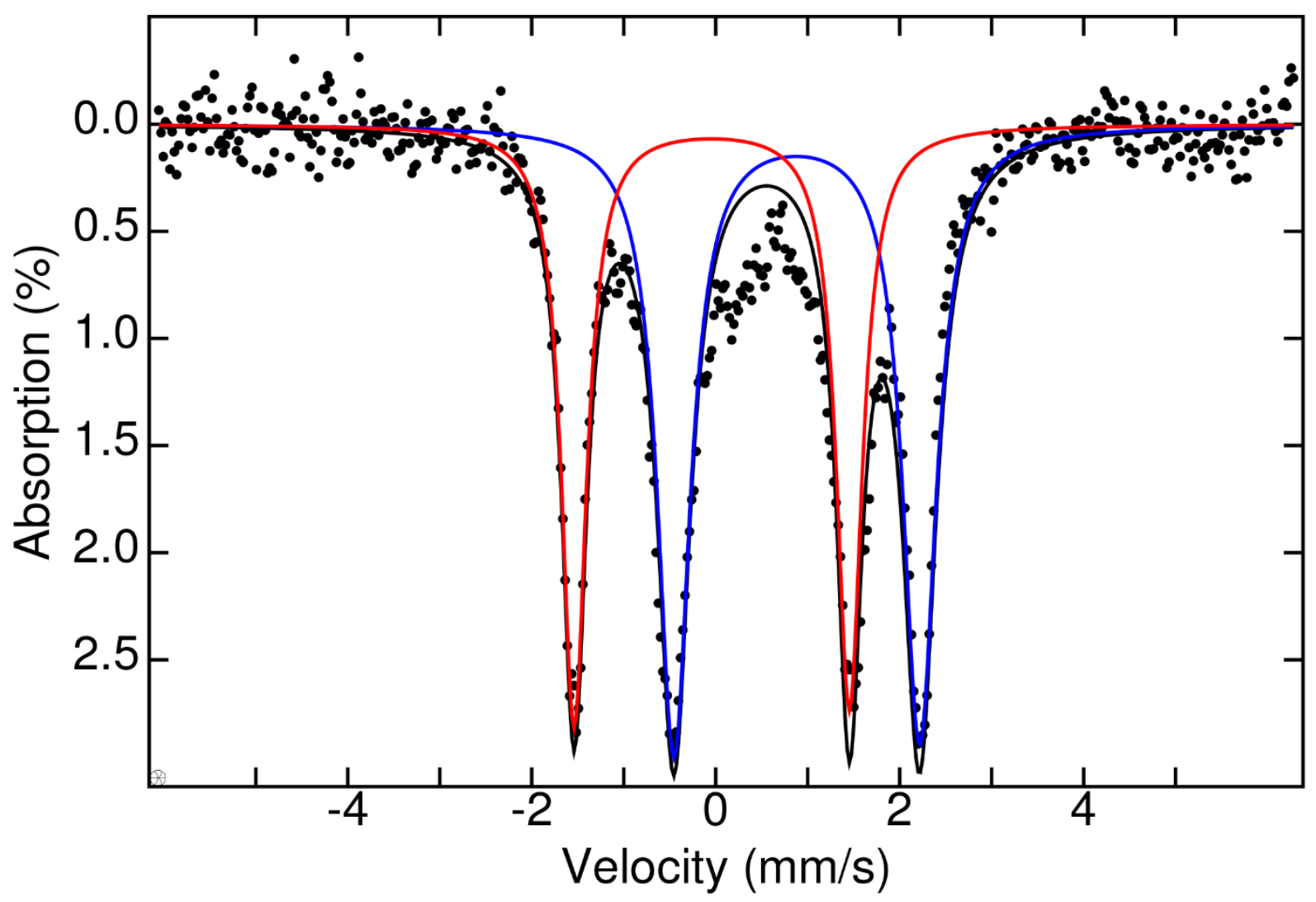

Figure S4. Solid state Mössbauer spectrum of $\left[\mathrm{Ph}_{2} \mathrm{~B}\left({ }^{\mathrm{t}} \mathrm{BuIm}\right)_{2} \mathrm{FeH}\right]_{2}$ at $80 \mathrm{~K}$. Black circles represent experimental data, while red and blue lines correspond to fits of the spectral data that is an alternative to that shown in Figure 2 (main text), as described in the text. 
Table S1. Mössbauer Spectral Parameters for Mononuclear Organometallic Fe(II) Complexes $(S=2)$ in a Tetrahedral Environment

\begin{tabular}{lllll}
\hline Complex & $\delta(\mathrm{mm} / \mathrm{s})$ & $\Delta E_{\mathrm{Q}}(\mathrm{mm} / \mathrm{s})$ & $\mathrm{T}(\mathrm{K})$ & $\mathrm{Ref}$ \\
\hline $\mathrm{Fe}($ depe $) \mathrm{Mes}_{2}$ & 0.39 & 1.71 & 80 & 4 \\
$\mathrm{Fe}\left(\mathrm{IEt}_{2} \mathrm{Me}_{2}\right)_{2} \mathrm{Ph}_{2}$ & 0.47 & 2.38 & 80 & 5 \\
$\mathrm{Fe}\left(\mathrm{IEt}_{2} \mathrm{Me}_{2}\right)_{2}\left(p-{ }^{\mathrm{t}} \mathrm{BuPh}\right)_{2}$ & 0.45 & 2.4 & 5 \\
$\mathrm{Fe}\left(\mathrm{IEt}_{2} \mathrm{Me}_{2}\right)_{2}\left(\mathrm{CH}_{2} \mathrm{SiMe}_{3}\right)_{2}$ & 0.49 & 2.53 & 5 \\
\hline
\end{tabular}

depe $=1,2-$ bis(diethylphosphino)ethane

$\mathrm{IEt}_{2} \mathrm{Me}_{2}=1,3$-diethyl-4,5-dmethylimidazol-2-ylidene

Table S2. Mössbauer Spectral Parameters for Mononuclear Organometallic Fe(II) Complexes $(S=1)$ in a Square Planar Environment.

\begin{tabular}{lllll}
\hline Complex & $\delta(\mathrm{mm} / \mathrm{s})$ & $\Delta E_{\mathrm{Q}}(\mathrm{mm} / \mathrm{s})$ & $\mathrm{T}(\mathrm{K})$ & Ref \\
\hline $\mathrm{Fe}\left(\mathrm{PEt}_{2} \mathrm{Ph}\right)_{2} \mathrm{Mes}_{2}$ & 0.31 & 4.63 & 80 & 4 \\
$\mathrm{Fe}($ dppe $) \mathrm{Mes}_{2}$ & 0.33 & 4.53 & & 4 \\
$\mathrm{Fe}\left(\mathrm{C}_{6} \mathrm{Cl}_{5}\right)_{2}\left(\mathrm{PEt}_{3}\right)_{2}$ & 0.29 & 4.16 & 79 & 6 \\
$\mathrm{Fe}\left(\mathrm{C}_{6} \mathrm{Cl}_{5}\right)_{2}\left(\mathrm{PEt}_{2} \mathrm{Ph}\right)_{2}$ & 0.25 & 4.13 & & 6 \\
$\mathrm{Fe}\left(\mathrm{IEt}_{2} \mathrm{Me}_{2}\right)_{2}\left(\left(3,5-\mathrm{CF}_{3}\right)_{2} \mathrm{C}_{6} \mathrm{H}_{3}\right)_{2}$ & 0.17 & 4.09 & 80 & 5 \\
\hline
\end{tabular}

dppp $=1,2-$ bis(diphenylphosphino)ethane)

$\mathrm{IEt}_{2} \mathrm{Me}_{2}=1,3$-diethyl-4,5-dmethylimidazol-2-ylidene 
Table S3. Mössbauer Spectral Parameters for Mononuclear Fe(II) Complexes $(S=2)$ in a Square Planar Environment.

\begin{tabular}{lllll}
\hline Complex & $\delta(\mathrm{mm} / \mathrm{s})$ & $\Delta E_{\mathrm{Q}}$ & $\mathrm{T}(\mathrm{K})$ & $\mathrm{Ref}$ \\
& & $(\mathrm{mm} / \mathrm{s})$ & & \\
\hline$\left[\mathrm{Na}_{2}\left(\mathrm{Et}_{2} \mathrm{O}\right)_{4}\right]\left[\mathrm{Fe}_{2}\left({ }^{(\mathrm{BuSi}(\mathrm{OSiMe}} \mathrm{O}_{2}\right)_{2}\right]$ & 0.91 & 0.37 & 80 & 7 \\
{$\left[\mathrm{CF}_{3}-\mathrm{ONO}\right] \mathrm{FeClLi}$} & & & \\
& 0.83 & 0.45 & 4.2 & 8 \\
\hline
\end{tabular}

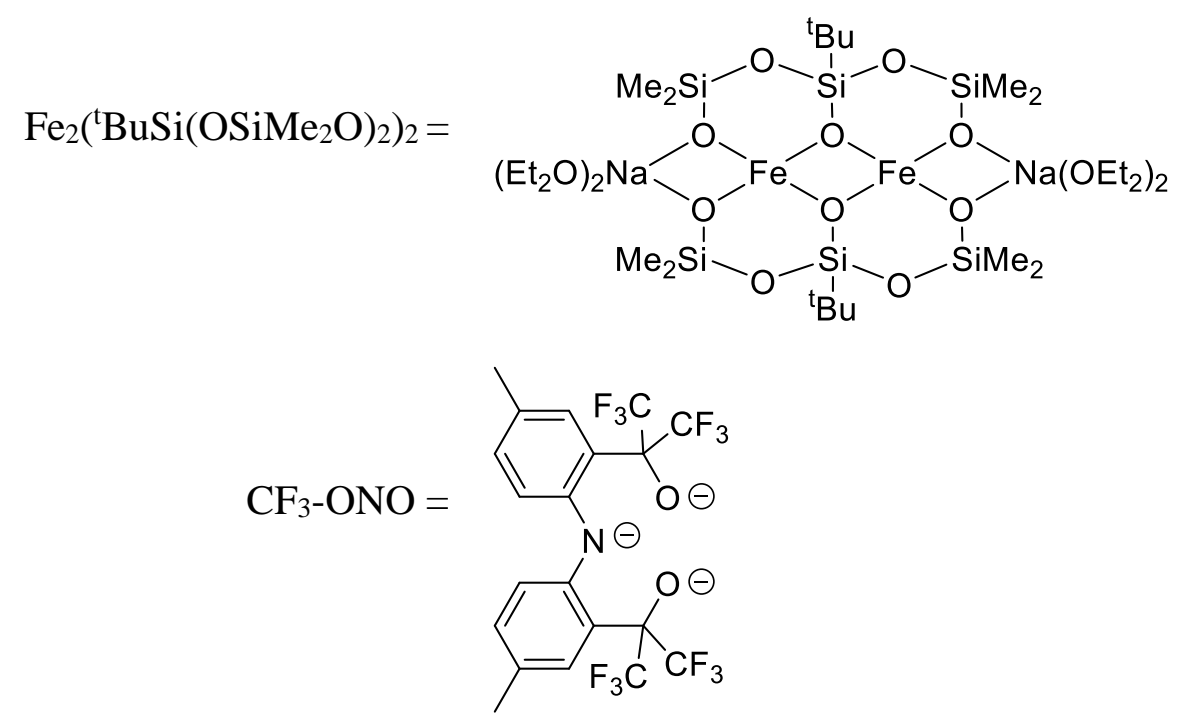


Table S4. Mössbauer Spectral Parameters for Mononuclear Fe(I) Complexes $(S=1 / 2)$ in a Square Planar Environment.

\begin{tabular}{lllll}
\hline Complex & $\delta(\mathrm{mm} / \mathrm{s})$ & $\Delta E_{\mathrm{Q}}(\mathrm{mm} / \mathrm{s})$ & $\mathrm{T}(\mathrm{K})$ & $\mathrm{Ref}$ \\
\hline $\mathrm{Fe}\left(\mathrm{I}^{\mathrm{i} P r} \mathrm{Me}_{2}\right)_{4}^{+}$ & 0.36 & 1.92 & $200^{\mathrm{a}}$ & 9 \\
$\mathrm{Fe}(\mathrm{TPP})^{-}$ & 0.65 & 2.23 & 77 & 10 \\
$\mathrm{~L}^{\mathrm{xyl}} \mathrm{Fe}(\mathrm{CO})_{2}$ & 0.18 & 2.04 & 80 & 11 \\
\hline
\end{tabular}

a - Spectrum is heavily broadened at $80 \mathrm{~K}$ due to slow paramagnetic relaxation.

$\mathrm{TPP}=$ tetraphenylporphyrin dianion

$\mathrm{I}^{\mathrm{i}} \mathrm{Pr}_{2} \mathrm{Me}_{2}=$ 1,3-bis(isopropyl) -4,5-dmethylimidazol-2-ylidene

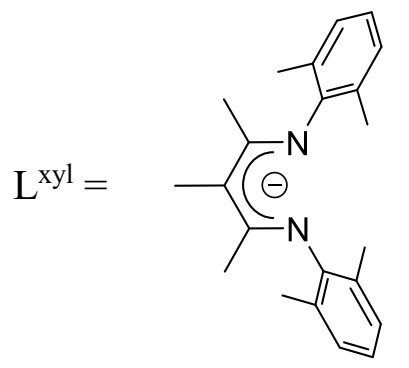


Table S5. Mössbauer Spectral Parameters for Mononuclear Fe(I) Complexes $(S=3 / 2)$ in a Tetrahedral Environment.

\begin{tabular}{lcccc}
\hline Complex & $\delta(\mathrm{mm} / \mathrm{s})$ & $\Delta E_{\mathrm{Q}}(\mathrm{mm} / \mathrm{s})$ & $\mathrm{T}(\mathrm{K})$ & $\mathrm{Ref}$ \\
\hline $\mathrm{L}^{\mathrm{Me}} \mathrm{Fe}\left({ }^{\mathrm{t} B u p y}\right)_{2}$ & 0.79 & 0.59 & 80 & 12 \\
$\mathrm{Fe}\left(\mathrm{IMe}_{2} \mathrm{Me}_{2}\right)_{4}{ }^{+}$ & 0.57 & 0.17 & 80 & 9 \\
$\mathrm{Fe}\left(\mathrm{IEt}_{2} \mathrm{Me}_{2}\right)_{4}^{+}$ & 0.57 & 0.82 & & 9 \\
\hline
\end{tabular}

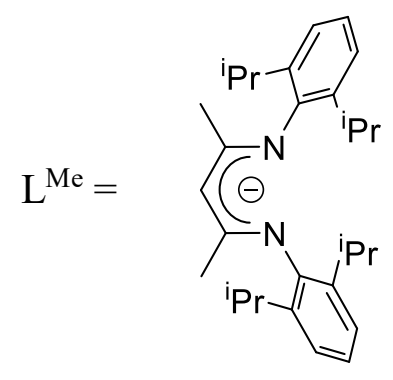

$\mathrm{IMe}_{2} \mathrm{Me}_{2}=1,3,4,5$-tetramethylimidazol-2-ylidene

$\mathrm{IEt}_{2} \mathrm{Me}_{2}=1,3$-diethyl-4,5-dmethylimidazol-2-ylidene 
Table S6. Mössbauer Spectral Parameters for Mononuclear Fe(III) Complexes.

\begin{tabular}{lllll}
\hline Complex & $\delta(\mathrm{mm} / \mathrm{s})$ & $\Delta E_{\mathrm{Q}}(\mathrm{mm} / \mathrm{s})$ & $\mathrm{T}(\mathrm{K})$ & $\mathrm{Ref}$ \\
\hline Square Planar $(S=3 / 2)$ & & & & \\
$\mathrm{Fe}(\mathrm{qdt})_{2}$ & 0.23 & 3.7 & 80 & 13 \\
$\mathrm{Fe}(\mathrm{TipsiPP})^{+}$ & 0.33 & 5.16 & 6 & 14 \\
Tetrahedral $(S=1 / 2)$ & & & & \\
$\mathrm{L}^{\mathrm{Me}} \mathrm{FeCl}_{2}$ & 0.29 & 1.79 & 80 & 15 \\
\hline
\end{tabular}

qdt $=o$-quinoxalinedithiolato.

TipsiPP = 5,10,15,20-tetrakis(2',6'-bis(triisopropylsiloxy)phenyl)porphyrin dianion.

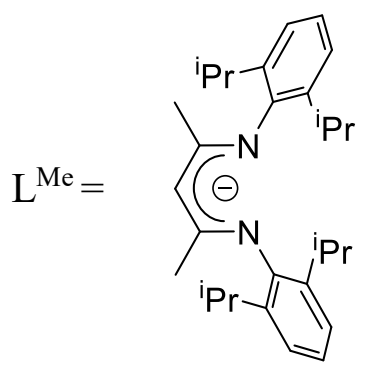


Table S7. Mössbauer Spectral Parameters for $\beta$-Diketiminate $\mathrm{Fe}_{2} \mathrm{H}_{2}$ and $\mathrm{Fe}_{2} \mathrm{D}_{2}$ Complexes.

\begin{tabular}{llllc}
\hline Complex & $\delta(\mathrm{mm} / \mathrm{s})$ & $\Delta E_{\mathrm{Q}}(\mathrm{mm} / \mathrm{s})$ & $T(\mathrm{~K})$ & Ref. \\
\hline$\left[\mathrm{L}^{\mathrm{Me}} \mathrm{FeH}\right]_{2}$ & 0.51 & 2.05 & 80 & 16 \\
{$\left[\mathrm{~L}^{\mathrm{Me}} \mathrm{FeD}\right]_{2}$} & 0.51 & 2.10 & & 16 \\
{$\left[\mathrm{~L}^{\mathrm{tBu}} \mathrm{FeH}\right]_{2}$} & 0.59 & 1.58 & 80 & 17 \\
{$\left[\mathrm{~L}^{\mathrm{tBu}} \mathrm{FeD}\right]_{2}$} & 0.58 & 1.74 & 80 & 16 \\
{$\left[\mathrm{~L}^{\mathrm{Me}, \mathrm{Et}} \mathrm{FeH}\right]_{2}$} & 0.66 & 1.27 & 80 & 18 \\
\hline
\end{tabular}
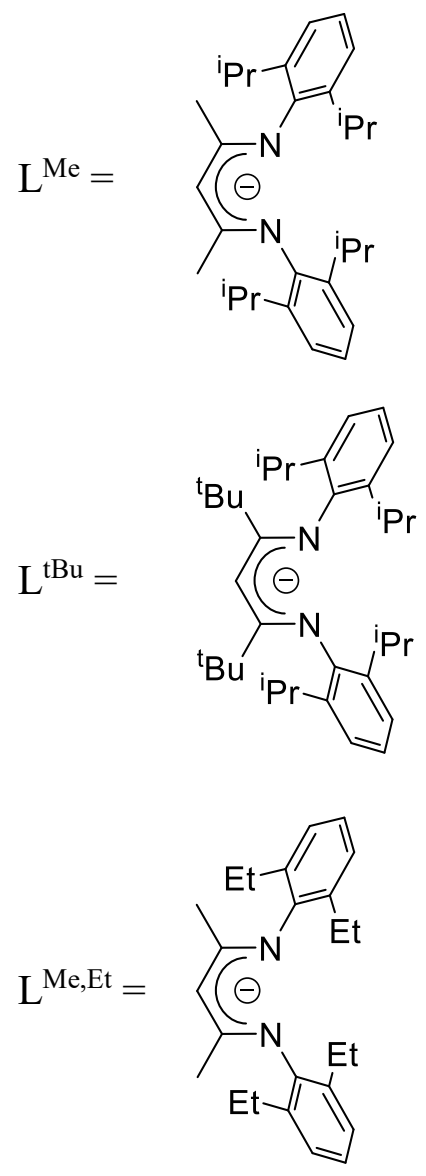


\section{Magnetic Measurements}

Magnetic measurements of $\left[\mathrm{Ph}{ }_{2} \mathrm{~B}\left({ }^{\mathrm{t}} \mathrm{BuIm}\right)_{2} \mathrm{FeH}\right]_{2}$ were performed on polycrystalline samples restrained with eicosane wax and flame-sealed in a quartz tube under vacuum. All data were collected using a Quantum Design MPMS-XL SQUID magnetometer from 1.8 to $300 \mathrm{~K}$ at applied dc fields ranging from 0 to $+7 \mathrm{~T}$. Dc susceptibility data were corrected for diamagnetic contributions from the eicosane wax and from the core diamagnetism of the sample (estimated using Pascal's constants $\left.{ }^{19}\right)$. 


\section{Electronic Absorption Spectra of $\left[\mathrm{Ph}_{2} \mathrm{~B}\left({ }^{\mathrm{t}} \mathrm{BuIm}\right)_{2} \mathrm{FeH}\right]_{2}$.}

The electronic absorption spectrum of $\left[\mathrm{Ph}_{2} \mathrm{~B}\left({ }^{\mathrm{t}} \mathrm{BuIm}\right)_{2} \mathrm{FeH}\right]_{2}$ is not especially rich, but does exhibit bands that are informative and consistent with the assignment to two Fe(II) ions, one being tetrahedral, high-spin $(S=2)$ and the other square planar, intermediate-spin $(S=1)$. The UV-VisNIR spectrum recorded in $\mathrm{C}_{6} \mathrm{D}_{6}$ (to mitigate $\mathrm{C}$-H overtone vibrational bands in the NIR) is shown in Figure S5. There are strong bands below $500 \mathrm{~nm}$, in particular one that is resolved at $356 \mathrm{~nm}$ $\left(\varepsilon=7000 \mathrm{~L} \mathrm{~mol}^{-1} \mathrm{~cm}^{-1}\right)$. These are attributed to ligand-to-metal-charge transfer (LMCT) bands, based on analogous complexes of both imidazolylidene (NHC) and pyrazolyl chelating ligands. ${ }^{20}$ Further into the UV region are bands that were not investigated, but are due to intra-ligand transitions. Of interest are the two bands in the Vis-NIR region: one at $585 \mathrm{~nm}\left(17080 \mathrm{~cm}^{-1} ; \varepsilon\right.$ $=1100 \mathrm{~L} \mathrm{~mol}^{-1} \mathrm{~cm}^{-1}$, although the tail of the CT bands likely contribute to its intensity) and a weak one at roughly $1190 \mathrm{~nm}\left(8400 \mathrm{~cm}^{-1} ; \varepsilon \approx 150 \mathrm{~L} \mathrm{~mol}^{-1} \mathrm{~cm}^{-1}\right)$. The first can be assigned to a d-d transition of the square planar Fe(II) ion and the latter either wholly or partly to a transition of the tetrahedral $\mathrm{Fe}(\mathrm{II})$ ion, in particular by analogy with four-coordinate organometallic $\mathrm{Fe}(\mathrm{II})$ complexes $^{5}$ of general type $\mathrm{FeL}_{2} \mathrm{R}_{2}$, where $\mathrm{L}=$ mono- or bidentate (i.e., $\mathrm{Fe}(\mathrm{LL}) \mathrm{R}_{2}$ ) NHC ligands and $\mathrm{R}=$ aryl or alkyl moieties. For example, two tetrahedral complexes reported by Deng and coworkers, where LL $=$ bidentate-NHC and $\mathrm{R}=$ aryl, exhibit broad NIR bands at $1330\left(7520 \mathrm{~cm}^{-1}\right)$ and $1410 \mathrm{~nm}\left(7090 \mathrm{~cm}^{-1}\right) .{ }^{21}$ This is because tetrahedral Fe(II) complexes exhibit a weak band in the NIR region due to the transition ${ }^{5} \mathrm{E} \rightarrow{ }^{5} \mathrm{~T}_{2}\left(T_{d}\right.$ point group symmetry; ${ }^{22}$ e.g., at $4800 \mathrm{~cm}^{-1}$ for $\left[\mathrm{FeCl}_{4}\right]^{2-}$ in a chloride melt). ${ }^{23}$ The ligand field of hydrocarbyl, hydride, and imidazolyl (NHC) donors is expected to be stronger than that of chloride ions, blue-shifting the transition as seen here and in previous cases. ${ }^{5,21}$ In addition, the symmetry of the tetrahedral site in these cases is more accurately given as only $C_{2 v}$. We have used a simple ligand-field theory (LFT) angular overlap 
model (AOM) to describe this transition. Use of the actual bond angles with idealized four-fold symmetry ( $\mathrm{C}$ donors at $\theta=46.54^{\circ}, \mathrm{H}$ donors at $141.85^{\circ}$, and $\phi=0,180^{\circ}, 90^{\circ}, 270^{\circ}$ for these in order) with AOM bonding parameters: $\varepsilon_{\sigma}(\mathrm{C})=8017 \mathrm{~cm}^{-1}, \varepsilon_{\sigma}(\mathrm{H})=5933 \mathrm{~cm}^{-1}$, and interelectronic repulsion (Racah) parameters: $B=700 \mathrm{~cm}^{-1}$ (reduced to $\sim 80 \%$ of the $\mathrm{Fe}^{2+}$ free-ion value) ${ }^{24} C=$ $3100 \mathrm{~cm}^{-1}\left(C / B=4.43\right.$, versus 4.32 in free-ion $\left.\mathrm{Fe}^{2+}\right){ }^{24}$ There is obviously no $\pi$-bonding for the hydrido ligands and for simplicity, we ignore $\pi$-bonding for the imidazolylidenes. Previous studies suggest that $\pi$-bonding, whether donating or accepting, is small for this ligand type. ${ }^{25}$ The sole reference point of which we are aware for a hydrido ligand in our context is the interesting homoleptic, low-spin $\left({ }^{1} \mathrm{~A}_{1 \mathrm{~g}}\right.$ ground state in $\left.\mathrm{O}_{h}\right)$ complex $\left[\mathrm{FeH}_{6}\right]^{4-} \cdot{ }^{26-28}$ The countercations are four $\left[\mathrm{MgX}(\mathrm{THF})_{2}\right]^{+}$, where $\mathrm{X}=\mathrm{Cl}$ or $\mathrm{Br}$, or a mixture of the two. The crystal structures of $\left[\mathrm{FeH}_{6}\right]^{4-}$ (CSD codes: BASLIQ, BASLIQ01, BASLIQ10) using both $x-$ ray $^{27,28}$ and neutron ${ }^{28}$ diffraction show direct interaction between the $\mathrm{Mg}$ (II) ions and hydrido ligands to $\mathrm{Fe}(\mathrm{II})$, forming a $\left[\mathrm{Mg}_{4} \mathrm{FeH}_{6}\right]^{4+}$ unit with the $\mathrm{Mg}(\mathrm{II})$ ions at the corners and the hydrides at the faces of a $\mathrm{Fe}(\mathrm{II})-$ centered cube..$^{27,28}$ A thorough investigation by Linn and Gibbins of the electronic absorption spectra of this complex in THF solution yielded $\varepsilon_{\sigma}(\mathrm{H})=8250 \mathrm{~cm}^{-1}$ (based on the midpoint of their range of $\Delta_{\mathrm{H}^{-}}$values). ${ }^{26} \mathrm{~A}$ hydrido ligand bridging between two $\mathrm{Fe}(\mathrm{II})$ ions would be expected to be a weaker donor than one bridging $\mathrm{Mg}$ (II) and $\mathrm{Fe}(\mathrm{II})$ ions since the interaction with $\mathrm{Mg}$ (II) is less covalent than with $\mathrm{Fe}(\mathrm{II})$ (some association of $\mathrm{Mg}(\mathrm{II})$ ions with the $\left[\mathrm{FeH}_{6}\right]^{4-}$ unit persists in THF solution $){ }^{26}$ so the estimate made here for $\varepsilon_{\sigma}(\mathrm{H})$ seems reasonable.

The situation with respect to the square planar site is even more challenging because of the dearth of truly analogous $\mathrm{Fe}(\mathrm{II})$ complexes (i.e., those lacking any axial ligands and without forced planar geometry). Many examples of macrocyclic (often tetrapyrroles) ${ }^{29} \mathrm{Fe}(\mathrm{II})$ complexes with such enforced square planar tetra-coordination are known. A rare example of the corresponding square 
planar Fe(III) with no axial ligands is that reported by Suslick and co-workers, ${ }^{14}\left[\mathrm{Fe}{ }^{\mathrm{III}}(\mathrm{TipsiPP})\right]^{+}$, where $\mathrm{H}_{2}$ TipsiPP is $5,10,15,20$-tetrakis(2',6'-bis(triisopropylsiloxy)phenyl)-porphyrin, an extremely sterically hindered porphyrin. This $3 \mathrm{~d}^{5}$ complex exhibits an $S=3 / 2$ ground state, which is analogous to the $S=1$ ground state proposed for the planar site in $\left[\mathrm{Ph}_{2} \mathrm{~B}\left({ }^{\mathrm{t}} \mathrm{BuIm}\right)_{2} \mathrm{FeH}\right]_{2}$. Moreover, the electronic absorption spectra of most such complexes are dominated by ligandcentered bands. There are also square planar complexes of Fe(II) with the appropriate geometry, such as the pincer complexes reported by Pascualini et al., ${ }^{8,30}$ but these have $S=2$ ground states, so that the spin-allowed electronic transitions are quite different. To apply the AOM, we treat this $\mathrm{Fe}(\mathrm{II})$ site as ideally planar, with the $z$-axis defined as normal to the molecular plane, to be consistent with a truly square $\left(D_{4 h}\right)$ complex; thus, $\theta=90^{\circ}$ for all four ligands. We define the $x$ axis as along the Fe-Fe vector; the $\angle \mathrm{H}-\mathrm{Fe}-\mathrm{H}$ is $84.89^{\circ}$ and $\angle \mathrm{C}-\mathrm{Fe}-\mathrm{C}$ is $87.14^{\circ}$, so we set $\phi=42.44^{\circ}$ and $317.56^{\circ}$ for the hydrido ligands, and $136.43^{\circ}$ and $223.57^{\circ}$ for the NHC donors. If the same Racah and bonding parameters are used as for the tetrahedral site (the latter rounded to $\varepsilon_{\sigma}(\mathrm{C})=$ $\left.8000 \mathrm{~cm}^{-1}, \varepsilon_{\sigma}(\mathrm{H})=5900 \mathrm{~cm}^{-1}\right)$, then the ground state is indeed a spin triplet with triplet excited states located at $14200-15600 \mathrm{~cm}^{-1}$ and at $19100-20000 \mathrm{~cm}^{-1}$ above the ground state. Spinallowed transitions to any among these could correspond roughly to the observed Vis band. To obtain a closer match, any of the relevant parameters $\left(\varepsilon_{\sigma}(\mathrm{H}), \varepsilon_{\sigma}(\mathrm{C}), B\right.$, or $\left.C\right)$ could be modified, which is an unreasonably large parameter space given the limited experimental data. Solely as an illustration, however, we allow $\varepsilon_{\sigma}(\mathrm{C})$ to vary, the justification being that the $\mu$-hydrido ligands bond equally to the two Fe(II) ions, and that the Racah parameters would be essentially the same for Fe(II) ions with the same donor set. An exact match to the observed band for the lowest of the above higher set of triplet states then obtains with $\varepsilon_{\sigma}(\mathrm{C})=6546.4 \mathrm{~cm}^{-1}$, with the other parameters unchanged from the values used previously. 
This choice of LFT parameters affords a triplet ground state with very low-lying quintet and singlet excited states. Their relative energies could be adjusted by changing the Racah parameters, although this ability is limited because an increase in the Racah parameters could make the ground state a singlet and a decrease would favor the quintet. The ground state can be described in strong field notation as $d_{x^{2}-y^{2}}{ }^{2} d_{x z}{ }^{2} d_{y z}{ }^{1} d_{z^{2}}{ }^{1} d_{x y}{ }^{0}$. Note that because the $x$-axis is defined between the bonds (along the Fe-Fe vector), $d_{x y}$ makes up the Fe-L $\sigma^{*} \mathrm{MO}$, rather than $d_{x^{2}-y^{2}}$. The modest deviation from four-fold symmetry leads to the $d_{x z}$ orbital being slightly lower in energy than $d_{y z}$. Using the $C_{2 v}$ point group with $C_{2}$ defined along $x$ rather than $z$, which we have done previously, ${ }^{31}$ means that this ground state is ${ }^{3} \mathrm{~A}_{2}$ rather than ${ }^{3} \mathrm{~B}_{2}$. There are a number of triplet excited state; however, the lowest lying are too close in energy to the ground state $\left(\sim 3900-6400 \mathrm{~cm}^{-1}\right)$ to be observable by optical spectroscopy and the next range, while in the NIR region $\left(\sim 11400-14000 \mathrm{~cm}^{-1}\right)$, involve multi-electron transitions, although these may contribute to the shoulder seen experimentally at $\sim 800 \mathrm{~nm}\left(\sim 12500 \mathrm{~cm}^{-1}\right)$. The next range of triplet excited states $(\sim 17080-17$ $800 \mathrm{~cm}^{-1}$ ), however, likely corresponds to the observed Vis transition as it includes dipole-allowed single-electron transitions. A complete listing of the electronic states of this AOM generated using the program Ligfield ${ }^{32}$ is given in Table S11. 


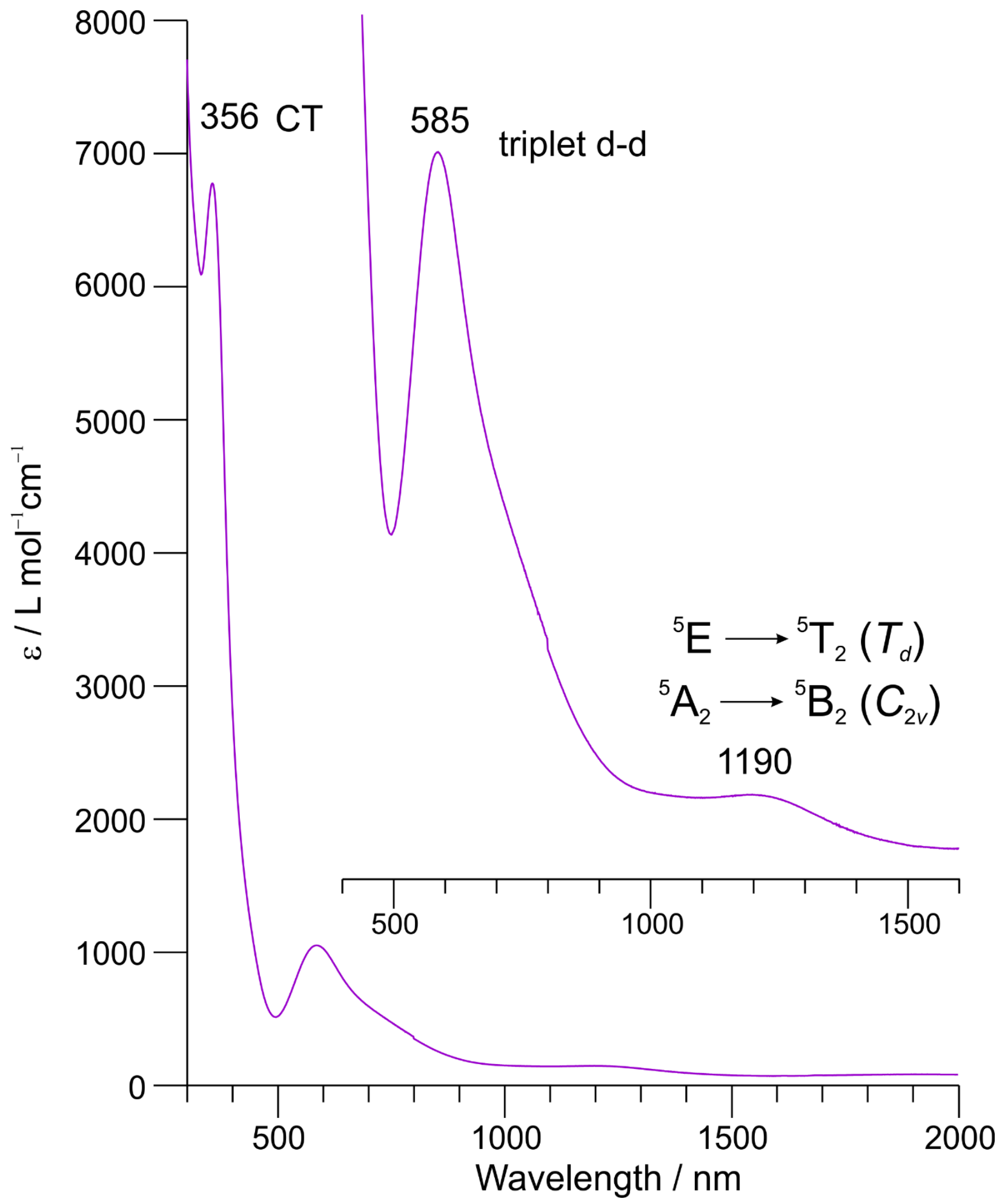

Figure S5. UV-Vis-NIR spectrum of $\left[\mathrm{Ph}_{2} \mathrm{~B}\left({ }^{\mathrm{t}} \mathrm{BuIm}\right)_{2} \mathrm{FeH}\right]_{2}$ in $\mathrm{C}_{6} \mathrm{D}_{6}$ solution. See text for discussion on band assignments. 


\section{HFEPR Spectroscopy}

High frequency and -field EPR (HFEPR) measurements were performed on a constrained powder sample of $\left[\mathrm{Ph}_{2} \mathrm{~B}\left({ }^{\mathrm{t}} \mathrm{BuIm}\right)_{2} \mathrm{FeH}\right]_{2}$. The series of frequency-dependent spectra recorded in the range of $208-634 \mathrm{GHz}$ at both $5 \mathrm{~K}$ and $20 \mathrm{~K}$ are shown in Figures S6a and S6b, respectively. The spectra recorded at $5 \mathrm{~K}$ and below $600 \mathrm{GHz}$ are dominated by lines which correspond to molecular oxygen and are marked by asterisks in Figure S6. We also observe a very weak feature (indicated by \#) near $g=2.00$ which originates from the presence of a minor radical contaminant. The final feature occurs at $g \sim 14$ (pink circle) and could arise from transitions within the $m_{S}= \pm 3$ quasidoublet. Such a transition would require that $D$ is negative, $E \neq 0$, and that $g_{z} \approx 2.3$. The narrow linewidth of this transition is unusual and seems inconsistent with the broad lines observed at higher frequencies (vide infra) but the large $g$-value precludes any of the normally observed containments, e.g. molecular oxygen and radical-based impurities. Thus we can assign it as originating from the compound of interest. In spectra recorded at $5 \mathrm{~K}$ and above $600 \mathrm{GHz}$ we observe a single transition which moves towards zero field as the frequency increases. Examining a pair of Zeeman diagrams (Figure S7) generated for both signs of $D$ suggests that both cases could produce such a transition at low temperatures (orange circle in Figure S6). Upon raising the temperature to $20 \mathrm{~K}$ we observe three additional lines, described as follows. The first line intercepts zero field at $\sim 208 \mathrm{GHz}$ and increases in field position with increasing frequency (red circle). The second line is observed in the 610 and $634 \mathrm{GHz}$ spectra and its resonance field increases with frequency (green circle). A third line is observed at moderate field values which moves toward lower fields as the frequency is increased (blue circle). We note that both axial cases $(D>0$ and $D$ $<0)$, which could describe the low temperature $(5 \mathrm{~K})$ behavior of the 610 and $634 \mathrm{GHz}$ spectra, fail to reproduce any of these additional higher temperature $(20 \mathrm{~K})$ lines. Thus, we can deduce the 
presence of a non-zero rhombic component to the anisotropy, i.e., $E \neq 0$. This is consistent with the assignment of the peak noted in pink (Figure S6). The HFEPR spectra were simulated using a standard $S=3$ spin-Hamiltonian:

$$
\widehat{H}_{\text {spin }}=\beta_{e} \overrightarrow{\mathbf{B}} \cdot \widetilde{\boldsymbol{g}} \cdot \widehat{\boldsymbol{S}}+D\left[\hat{S}_{z}^{2}-\frac{S(S+1)}{3}+\frac{E}{D}\left(\hat{S}_{x}^{2}-\hat{S}_{y}^{2}\right)\right]+B_{4}^{0} \hat{O}_{4}^{0},
$$

where $\beta_{\mathrm{e}}$ is the Bohr magneton, $\overrightarrow{\mathbf{B}}$ is the magnetic field vector, $\widetilde{\boldsymbol{g}}$ is the g-tensor, $D / E$ are the second order axial and rhombic zfs parameters, $B_{4}^{0}$ is the fourth order axial zero field splitting (defined by $\left.\hat{O}_{4}^{0}\right)$ parameter, $\widehat{\boldsymbol{S}}$ is the total electronic spin operator, and $\hat{S}_{\mu}(\mu=x, y, z)$ its components. During our efforts to simulate the spectra, we noticed that the prominent transitions all seemed to occur with $B_{0}$ parallel to the $z$ component of the anisotropy axis. Thus, we initially simulated the data using a single orientation. This procedure furnished the following set of parameters: $D=-7.1 \mathrm{~cm}^{-1}$, $|E|=2.1 \mathrm{~cm}^{-1}\left(|E / D|=0.30\right.$ ), $B_{4}^{0}=0.0055 \mathrm{~cm}^{-1}$, and $g_{z}=2.30$ (Figure S8). We then used these parameters to simulate the powder averaged spectrum which successfully reproduced essentially all the observed features. The values for $g_{x}$ and $g_{y}$ were then adjusted to reproduce the peaks which were missed with the initial parameterization and resulted in $g_{x}=2.00$ and $g_{y}=2.15$ (Figure S9). Efforts to reproduce the data without $B_{4}^{0}$ were significantly less promising and led to too large a difference in resonance position between the peaks noted in orange and green (Figure S6).

In addition to the $\left[\mathrm{Ph}_{2} \mathrm{~B}\left({ }^{(} \mathrm{BuIm}\right)_{2} \mathrm{FeH}\right]_{2}$ compound, we have also studied an isotopolog wherein the bridging hydrides are replaced by deuterides. Given the sensitivity of EPR to changes in spin Hamiltonian parameters, we would expect any changes in structure and/or the exchange interaction as a result of H-to-D substitution to manifest in the EPR spectrum. Spectra of $\left[\mathrm{Ph}_{2} \mathrm{~B}\left({ }^{\mathrm{t}} \mathrm{BuIm}\right)_{2} \mathrm{FeD}\right]_{2}$ are reported in Figure $\mathrm{S} 10$. Comparison of the spectra of the deuterated and 
protonated samples reveal no discernable changes in resonance positions. Thus, we find that no isotope effects exist in this $\mu-\mathrm{H}_{2}$ complex.
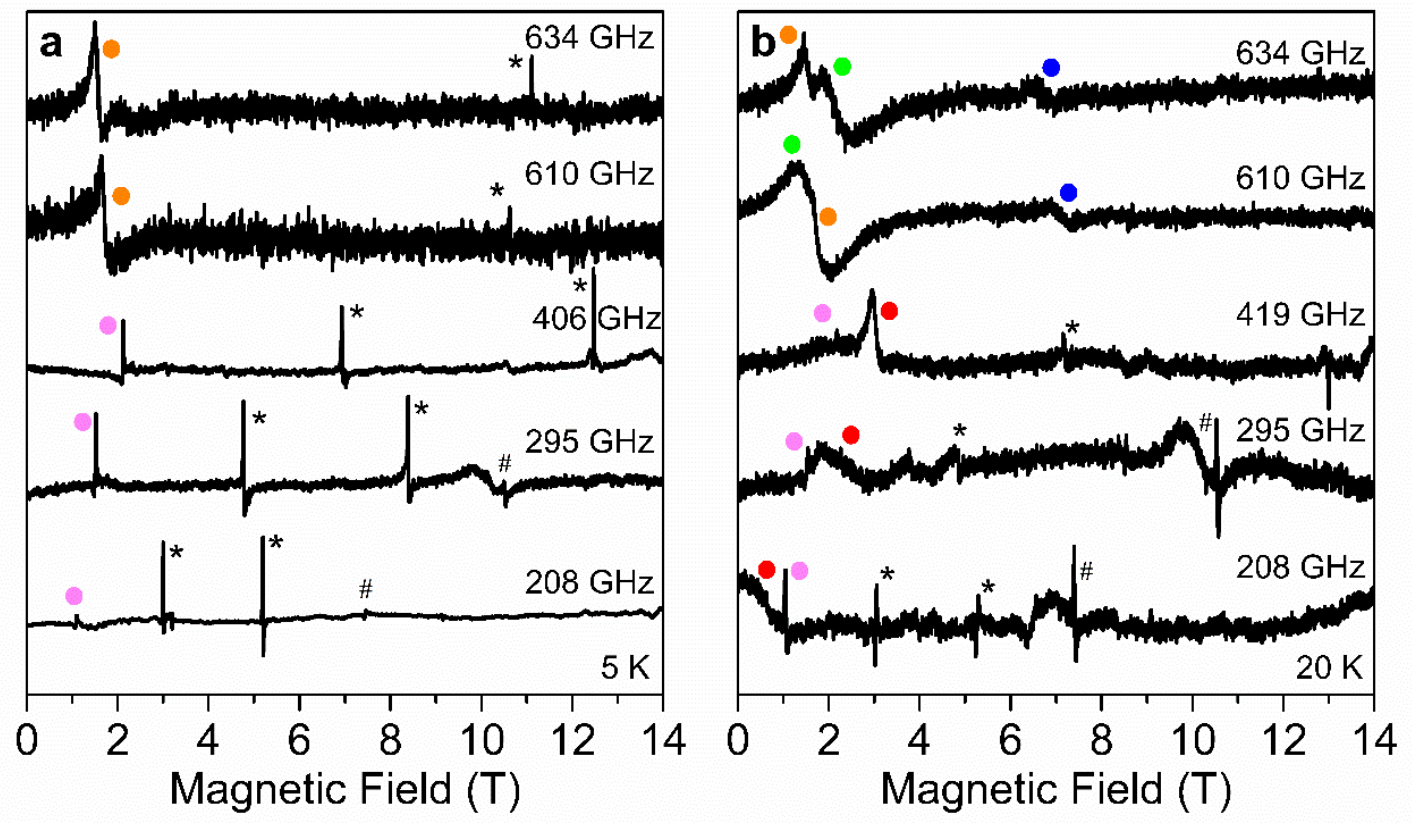

Figure S6: HFEPR spectra of a constrained sample of $\left[\mathrm{Ph}_{2} \mathrm{~B}\left({ }^{\mathrm{t}} \mathrm{BuIm}\right)_{2} \mathrm{FeH}\right]_{2}$ recorded at multiple frequencies at $5 \mathrm{~K}$ (a) and $20 \mathrm{~K}$ (b). The color markers are from the di-Fe(II) complex and are described in the accompanying text; asterisks indicate signals due to $\mathrm{O}_{2}(\mathrm{~s})$; a minor radical impurity is denoted by \#. 

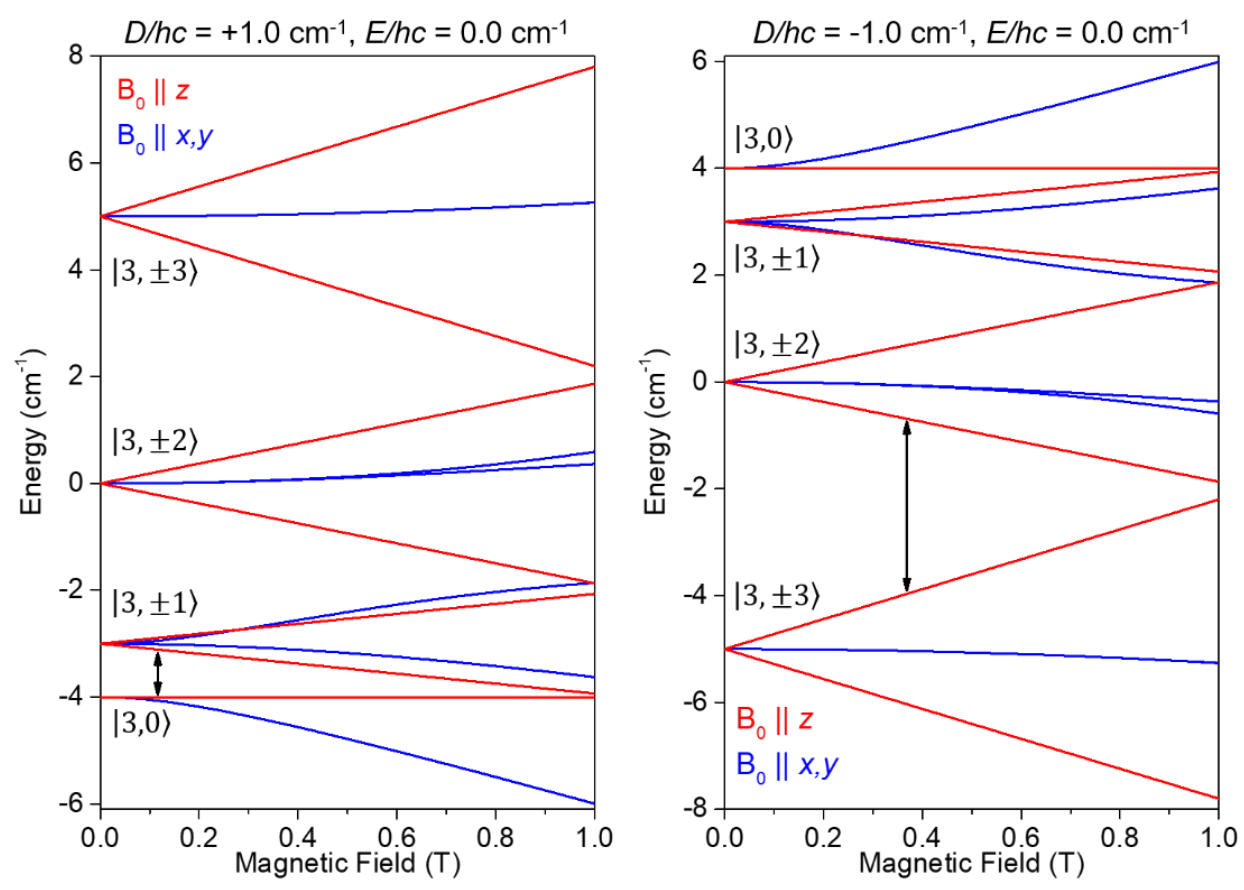

Figure S7: Zeeman diagrams of the two cases of axial zero field splitting: $D>0$ (left) and $D<0$ (right). The black double-sided arrows show the transitions from the ground $m_{S}$ state which decrease in field as the applied frequency is increased. 


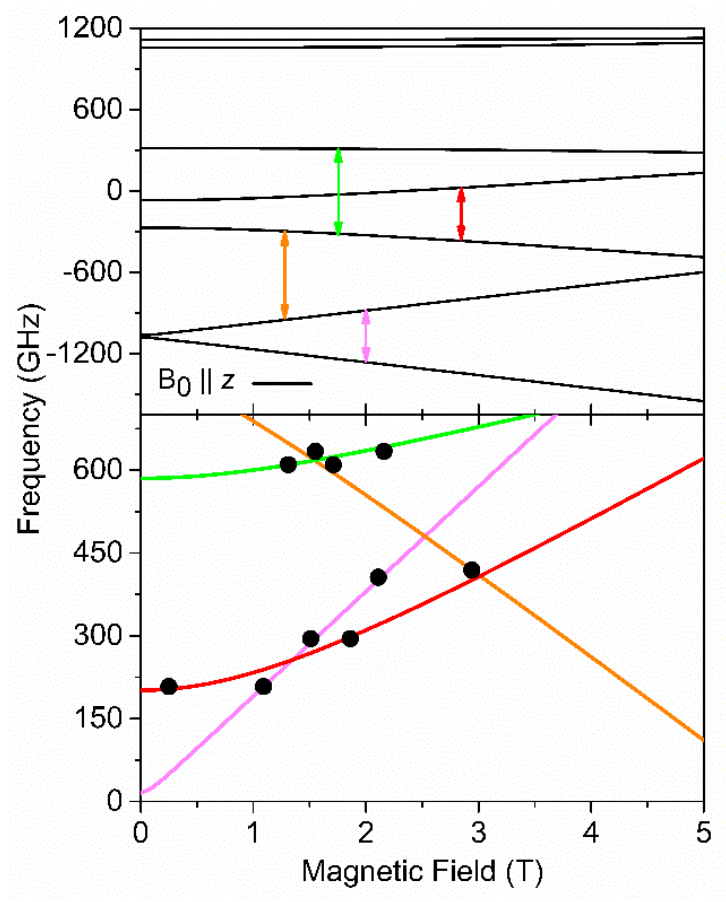

Figure S8: Zeeman diagram for $B_{0}$ parallel to the $z$ component of the anisotropy axis using the spin Hamiltonian parameters in the text. The colored arrows correspond to the assignment of the peak indicated by the same color in Figure S6 (Top). The bottom set of axes show the frequency dependence of the transitions with the same color coding as in the top panel. The solid black circles represent the experimentally observed frequency/resonant position combinations. 


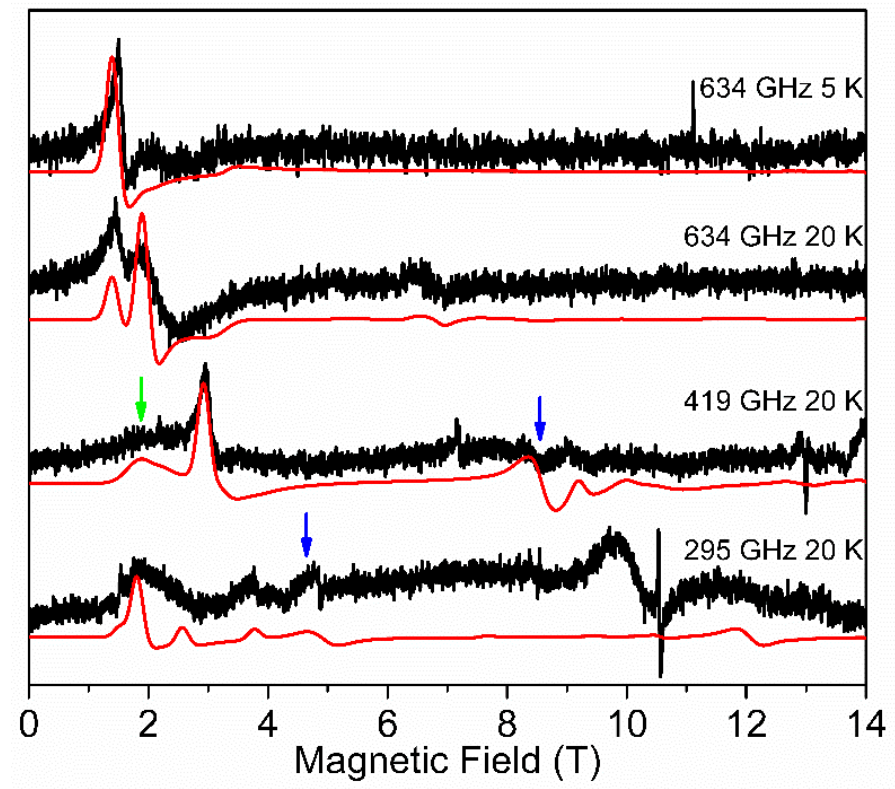

Figure S9: Experimental HFEPR spectra (black traces) and simulations (red traces) generated using the spin Hamiltonian parameters described in the text. The green and blue arrows indicate transitions which were used to determine $g_{x}$ and $g_{y}$ respectively. 


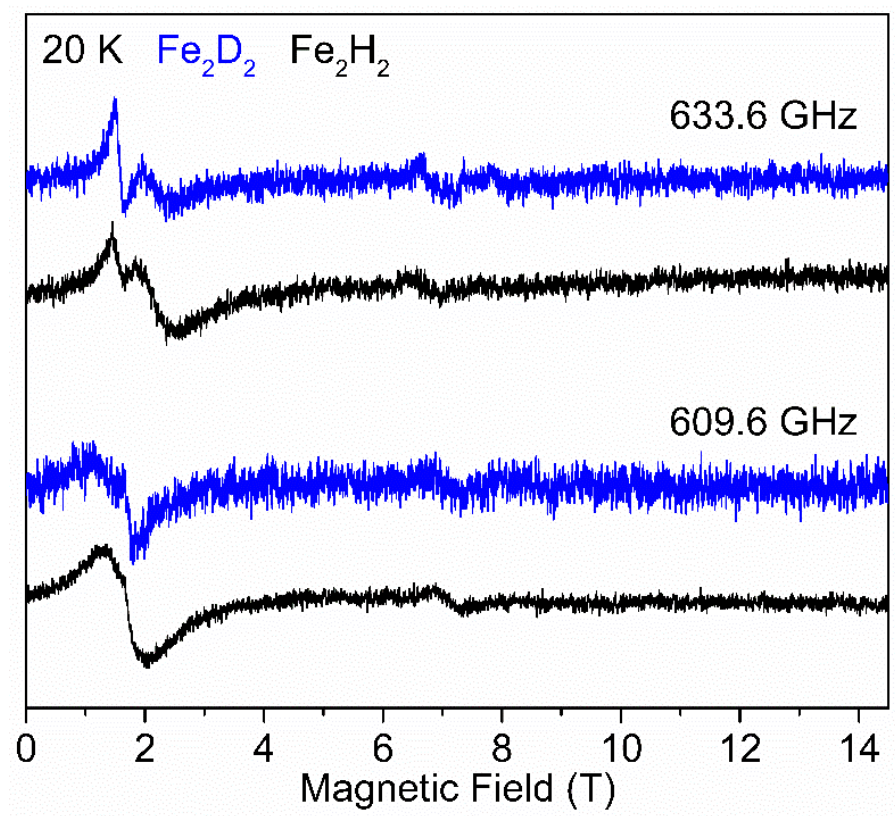

Figure S10: Comparison of HFEPR spectra between two isotopolog samples of $\left[\mathrm{Ph}_{2} \mathrm{~B}\left({ }^{\mathrm{B}} \mathrm{BuIm}\right)_{2} \mathrm{Fe}^{1,2} \mathrm{H}\right]_{2}$. The black trace is for the di-protide (natural abundance) isotopolog and the blue trace is for the di-deuteride isotopolog. 


\section{Electronic Structure Calculations}

All calculations were performed using density functional theory as implemented in the ORCA 3.0.3 computational software package. ${ }^{33}$ Evaluation of the electronic energies (single point energy) was done with the def2-TZVP ${ }^{34}$ basis set for Fe and all atoms bound to Fe; all other atoms were treated with the smaller def2-SVP basis set. For Mössbauer calculations, both Fe centers were given the $\mathrm{CP}(\mathrm{PPP})$ basis set, which includes additional polarization functions to better represent the electron density at the Fe centers. It is well known that geometric changes have large effects on magnetic properties, ${ }^{35}$ therefore single point energies were taken from the experimentally determined crystal structure. Calculation of the magnetic exchange parameters, based on $H=$ $-2 J \cdot S_{\mathrm{A}} \cdot S_{\mathrm{B}}$, were performed under all possible coupling regimes using broken symmetry ${ }^{36-38}$ DFT (BS-DFT) as implemented in ORCA. BP86 and B3LYP functionals were used to compare to experimental data as summarized in Table S8.

Table S8: Calculated exchange coupling constants $\left(J\right.$, in $\left.\mathrm{cm}^{-1}\right)$ at the def2-TZVP level of theory.

\begin{tabular}{lcc}
\hline (calculation method) & \multicolumn{2}{c}{$J$ calc. with functional } \\
\cline { 2 - 3 } & BP86 & B3LYP \\
\hline$J(\operatorname{method} 1)$ & 316.94 & 145.94 \\
$J(\operatorname{method} 2)$ & 237.03 & 109.45 \\
$J(\operatorname{method} 3)$ & 346.29 & 163.54 \\
Experimental & & 110 \\
\hline
\end{tabular}


Three different equations have been proposed to properly calculate the exchange coupling constant, $J$. The first (method 1 in Table S8) was proposed by Noodleman et al., ${ }^{36}$ and advocates for the weak interaction limit of coupling, while the second (method 2 in Table S8) is the opposite extreme, the strong coupling regime. The third (method 3 in Table S8), proposed by Yamaguchi and co-workers is more robust and will reduce to the method 1 value for the weak limit and the method 2 value for strong coupling. ${ }^{38}$ All three calculated $J$ values are presented in Table S8 for completeness.

Calculation of the coupling constants clearly shows a dependence on the percentage of HartreeFock (HF) exchange included in the functional. The pure GGA functional, BP86, which has no HF exchange overestimates the coupling constant by approximately 100 to $200 \mathrm{~cm}^{-1}$, depending on the method used. The addition of HF exchange into the functional (B3LYP) provides values that are more consistent with the experimentally determined exchange coupling constant of 110 $\mathrm{cm}^{-1}$.

The Yamaguchi equation ${ }^{38}$ can be used to pinpoint the origin of the calculated exchange coupling constant differences for BP86 and B3LYP:

$$
J_{a b}=-\frac{E_{H S}-E_{B S}}{\left\langle S^{2}\right\rangle_{H S}-\left\langle S^{2}\right\rangle_{B S}}
$$

where $E_{H S}$ is the energy of the high spin state, $E_{B S}$ is the energy of the broken symmetry state, $\left\langle S^{2}\right\rangle_{H S}$ is the expectation value for the $\hat{S}^{2}$ operator for the high spin state and $\left\langle S^{2}\right\rangle_{B S}$ is the expectation value for the $\hat{S}^{2}$ operator for the broken symmetry spin state. For this system, the high spin $(S=3)$ state will have a septet spin multiplicity and the broken symmetry state will be a triplet $(S=1)$. 
The large difference in calculated coupling constants results from the BP86 and B3LYP functionals converging to two different BS states. Comparing the overlap, S, via a corresponding orbital transformation, illustrates the differences between the two BS states (Table S9). The corresponding orbital number 245 has more overlap for BP86 than for B3LYP, suggesting that the magnetic pair are more strongly coupled for the BS state in BP86. The greater overlap leads to stronger coupling, and thus the pure GGA functional BP86 overestimates the exchange coupling constant. By contrast, this overlap is reduced for B3LYP, which weakens the coupling and decreases the coupling constant to a value that is closer to that determined experimentally. This is because functionals with increased HF exchange will better stabilize electronic states having unpaired spins. Therefore, the energy difference between the high spin state and the broken symmetry state is much larger for BP86 than for B3LYP. This larger energy difference between the HS and BS states leads to larger exchange coupling constants.

Table S9: Overlap (S) calculated for the magnetic corresponding orbitals for BP86 and B3LYP.

\begin{tabular}{lcc}
\hline & \multicolumn{2}{c}{ S calc. with functional } \\
\hline Orbital Number & BP86 & B3LYP \\
\hline 245 & 0.43811 & 0.09453 \\
246 & 0.04096 & 0.01022 \\
247 & 0.00000 & 0.00000 \\
248 & 0.00000 & 0.00000 \\
\hline
\end{tabular}


In general, when the HS and BS states have unpaired electrons, adding HF exchange is expected to decrease the exchange coupling constant $J$ by decreasing the energy between the two states. Pure GGA functionals like BP86 will provide larger exchange coupling constants when both states have unpaired electrons. Clearly, for this system, inclusion of HF exchange is vital to correctly describing the electronic structure of the BS state that is required for calculating the exchange coupling constants.

Mössbauer calculations were also performed with both BP86 and B3LYP functionals. In this case, the differences in the isomer shift $\delta$ and the quadrupolar splitting $\Delta E_{Q}$ calculated for the two functionals is not as drastic as for the exchange coupling constants (Table S10). In general, added HF exchange shows little to no improvement over the pure GGA BP86 functional. The experimental Mössbauer data for the tetrahedral center are $\delta=0.51, \Delta E_{Q}=1.92 \mathrm{~mm} / \mathrm{s}$ and for the square planar center: $\delta=0.35, \Delta E_{Q}=3.77 \mathrm{~mm} / \mathrm{s}$.

Table S10: Mössbauer data $(\mathrm{mm} / \mathrm{s})$ calculated at the CP(PPP)/def2-TVZP/def2-SVP level of theory. The CP(PPP) basis set was used for Fe, def2-TZVP for all atoms connected to the Fe, and def2-SVP for all other atoms.

\begin{tabular}{lccc}
\hline Parameter & BP86 & B3LYP & Experimental \\
\hline$\delta$ & & & \\
$\mathrm{Fe}\left(T_{d}\right)$ & 0.372 & 0.382 & 0.51 \\
$\mathrm{Fe}(\mathrm{SP})$ & 0.151 & 0.191 & 0.35 \\
$\Delta E_{Q}$ & & & \\
$\mathrm{Fe}\left(T_{d}\right)$ & -1.835 & -2.149 & 1.92 \\
$\mathrm{Fe}(\mathrm{SP})$ & 3.889 & 3.451 & 3.77 \\
\hline
\end{tabular}


For the tetrahedral iron center, the isomer shift is qualitatively the same for both functionals, however the $\delta$ value determined using B3LYP has a slightly larger deviation from experimental values than is typically observed. A newer linear model has been proposed for the calculation of isomer shift that may help to adjust the isomer shift value but was not pursued for this system. ${ }^{39}$ In the case of the square planar iron center, both functionals have similar errors. Despite these differences, it is important to note that both functionals predict the experimentally observed trends for the isomer shift and quadrupolar splitting values 


\section{Molecular Orbital Analysis}

As described in the main text, the orbital diagram for the $C_{2 v} \mathrm{~L}_{2} \mathrm{Fe}_{2}$ fragment was constructed from two orthogonal $\mathrm{L}_{2} \mathrm{Fe}$ fragments (Figure $\mathrm{S} 11$ ). In addition to the simplifications and assumptions discussed in the manuscript, for the sake of clarity, we have also assumed that orbital energies of the two iron fragments will be the same. In reality, this is not the case because the iron ligand bond lengths in for square planar site are shorter than those for the tetrahedral site.

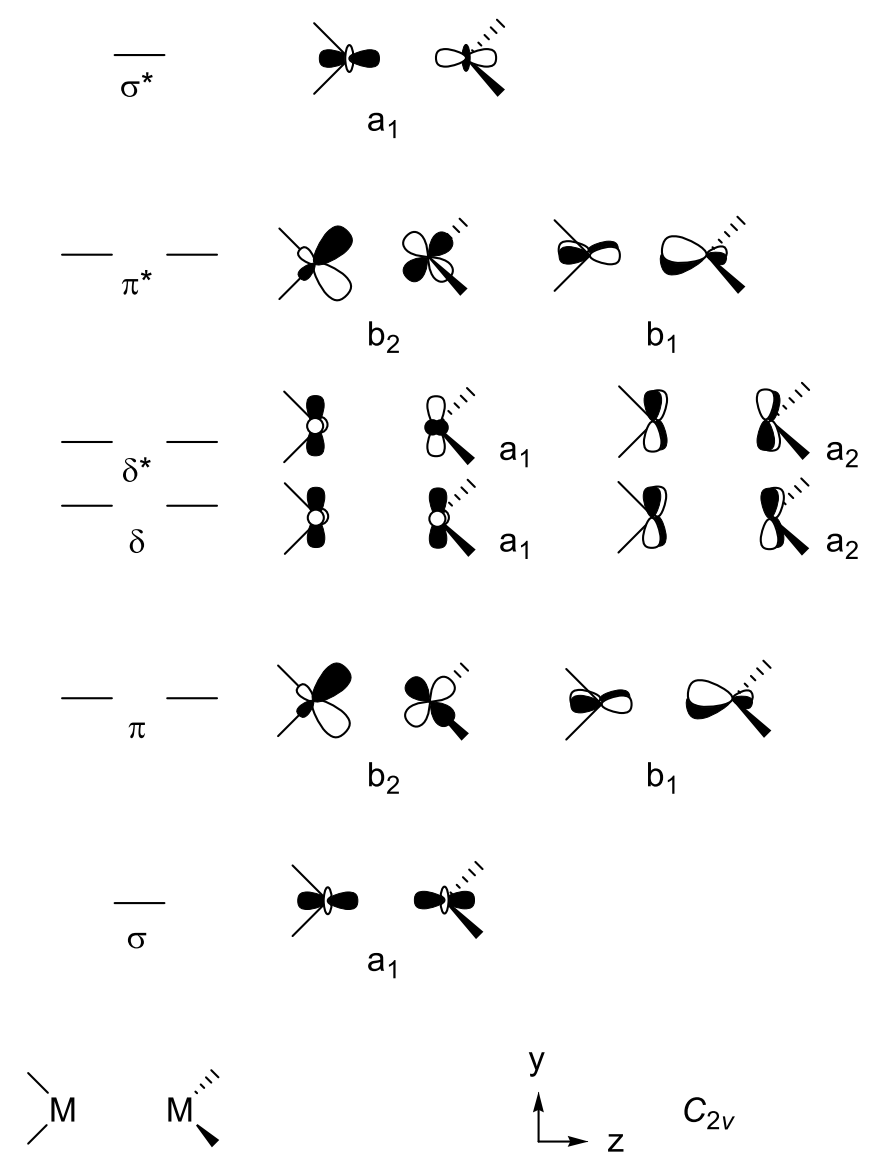

Figure S11. MO diagram for $C_{2 v} \mathrm{~L}_{2} \mathrm{Fe}_{2}$ fragment, including orbital representations. 
As described in the main text, the frontier orbitals of $\left[\mathrm{Ph}_{2} \mathrm{~B}\left({ }^{(} \mathrm{BuIm}\right)_{2} \mathrm{FeH}\right]_{2}$ determined by DFT computations have $\sigma, \pi$, and $\delta$ character with respect to the $\mathrm{Fe} \cdots \mathrm{Fe}$ interaction (Figure $\mathrm{S} 12$ ), however the low symmetry allows for orbital mixing that makes direct correspondence with the qualitative approach difficult. This orbital mixing has also hindered efforts to use multireference calculations.

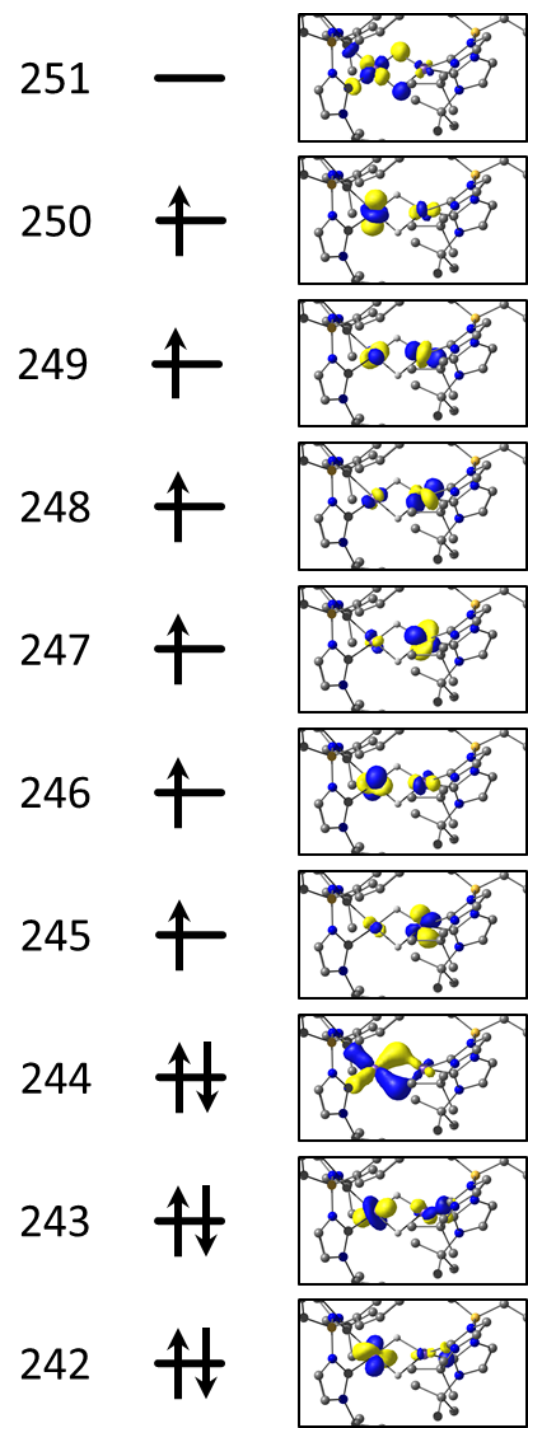

Figure S12. Unrestricted natural orbitals (UNOs) calculated for $\left[\mathrm{Ph}{ }_{2} \mathrm{~B}\left({ }^{\mathrm{t}} \mathrm{BuIm}\right)_{2} \mathrm{FeH}\right]_{2}$. Orbital numbers shown. 
The magnetic properties of $\left[\mathrm{Ph}_{2} \mathrm{~B}\left({ }^{\mathrm{t}} \mathrm{BuIm}\right)_{2} \mathrm{FeH}\right]_{2}$ are to be contrasted with those of $\mathrm{L}_{2} \mathrm{Fe}_{2} \mathrm{H}_{2}$ complexes with approximate $D_{2 h}$ symmetry. While a number of these complexes have been reported, the ground spin states of these complexes appear to be unknown, although room temperature solution magnetic moment data suggest antiferromagnetic coupling. ${ }^{16,18,40}$ This antiferromagnetic coupling can also be rationalized by a qualitative MO diagram. As with $\left[\mathrm{Ph}_{2} \mathrm{~B}\left({ }^{\mathrm{t}} \mathrm{BuIm}\right)_{2} \mathrm{FeH}\right]_{2}$, a $\mathrm{L}_{2} \mathrm{Fe} \cdots \mathrm{FeL}_{2}$ fragment is constructed from two $\mathrm{L}_{2} \mathrm{Fe}$ fragments that are aligned along the $z$-axis (Figure S13). Here, the two $\mathrm{L}_{2} \mathrm{Fe}$ fragments are coplanar. The resulting $\mathrm{L}_{2} \mathrm{Fe}^{\cdots} \cdots \mathrm{FeL}_{2}$ unit also has orbitals with $\sigma, \pi$, and $\delta$ symmetry, however the two $\pi$ orbitals are not degenerate: the $\pi$ orbital formed from the $\mathrm{d}_{\mathrm{yx}} \mathrm{p}_{\mathrm{y}}$ hybrids will be better stabilized than that formed from the $\mathrm{d}_{\mathrm{xz}}$ orbital due to better orbital overlap. The corresponding $\pi^{*}$ orbitals will therefore also be non-degenerate.

The full MO diagram is generated by combining the $\mathrm{L}_{2} \mathrm{Fe} \cdots \mathrm{FeL}_{2}$ fragment with an orthogonal $2 \mathrm{H}$ unit (Figure S14). Here, the Fe-Fe $\sigma$ bonding orbital $\left(a_{g}\right)$ is best suited for interaction with the $a_{g} \mathrm{H} 1 \mathrm{~s}$ combination, while the $\pi_{\mathrm{xz}}\left(b_{3 u}\right)$ orbital has the best interaction with the $b_{3 u} \mathrm{H} 1 \mathrm{~s}$ combination. As with $\left[\mathrm{Ph}_{2} \mathrm{~B}\left({ }^{\mathrm{t}} \mathrm{BuIm}\right)_{2} \mathrm{FeH}\right]_{2}$, additional orbital mixing has been ignored in the interest of clarity. Due to greater orbital overlap, we suggest that the $\pi^{*}\left(b_{3 u}\right)$ is sufficiently destabilized to favor spin pairing and a singlet ground state. Additional destabilization of this orbital by mixing with the $\delta * b_{3 u}$ orbital is also possible. 


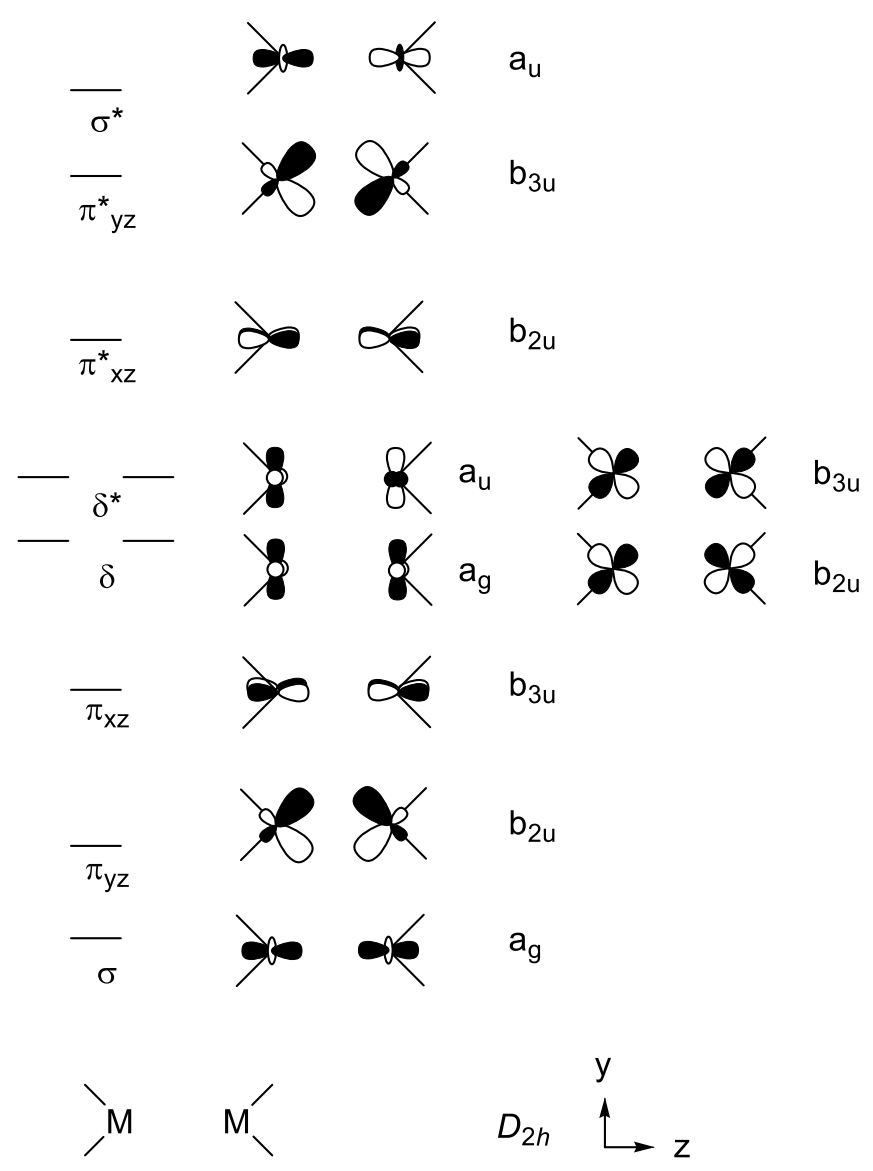

Figure S13. Fragment orbitals for the $\mathrm{L}_{2} \mathrm{Fe}_{2}$ unit in $D_{2 h}$ symmetry. 


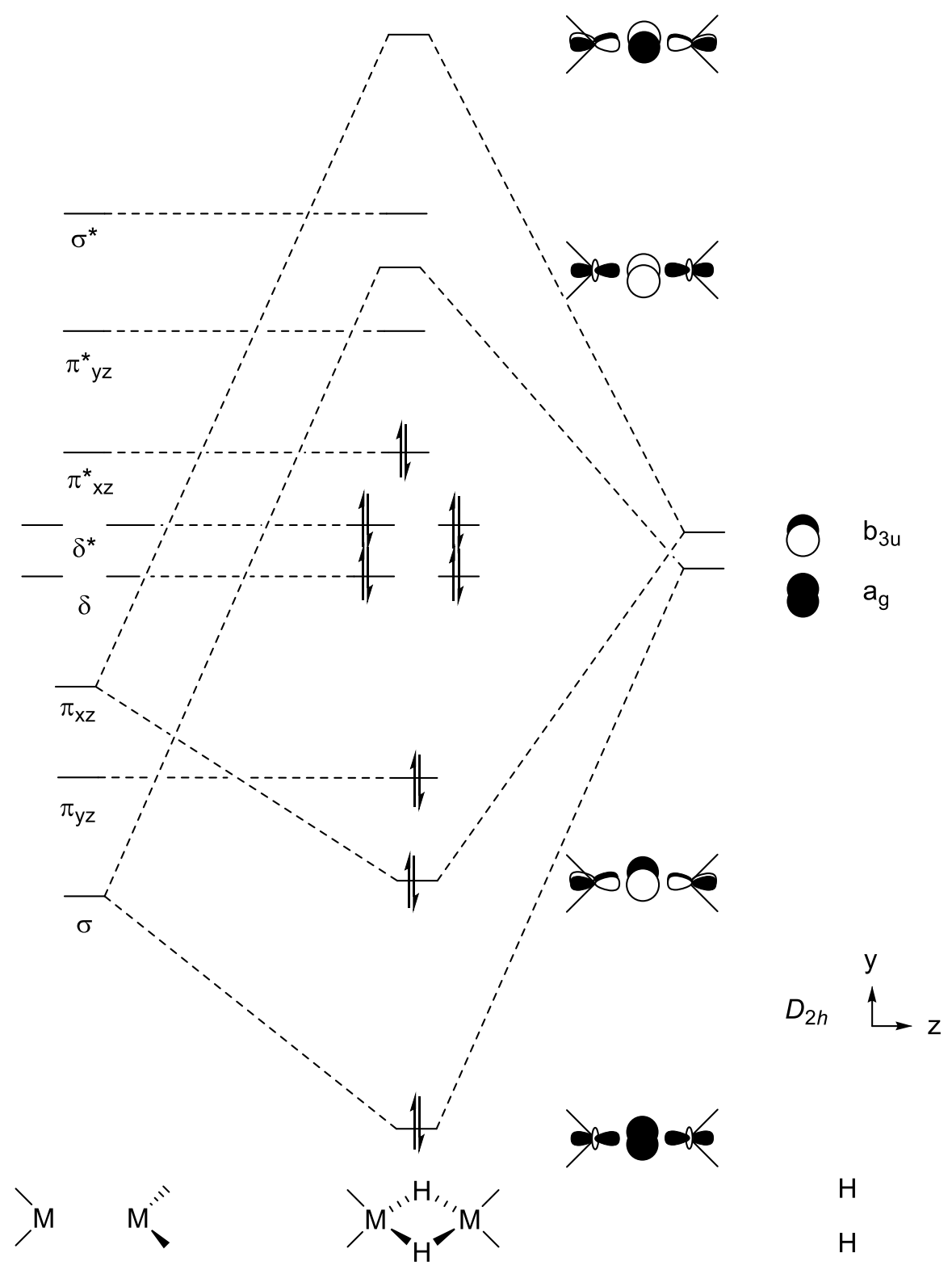

Figure S14. Fragment of orbitals for the $\mathrm{L}_{2} \mathrm{Fe}_{2}$ unit in $D_{2 h}$ symmetry. 


\section{X-ray Crystallography}

Empirical formula

Formula weight

Crystal color, shape, size

Temperature

Wavelength

Crystal system, space group

Unit cell dimensions

Volume

Z

Density (calculated)

Absorption coefficient

$\mathrm{F}(000)$

Data collection

Diffractometer

Theta range for data collection

Index ranges

Reflections collected

Independent reflections

Observed Reflections

Completeness to theta $=27.55^{\circ}$

Solution and Refinement

Absorption correction

Max. and min. transmission

Solution

Refinement method

Weighting scheme

Data / restraints / parameters

Goodness-of-fit on $\mathrm{F}^{2}$

Final $\mathrm{R}$ indices [I>2sigma(I)]

$\mathrm{R}$ indices (all data)

Largest diff. peak and hole
C52 H66 B2 Fe2 N8

936.45

green plate, $0.27 \times 0.25 \times 0.07 \mathrm{~mm}^{3}$

150(2) K

$0.71073 \AA$

Triclinic, P-1

$a=10.8558(4) \AA$

$\alpha=72.7024(18)^{\circ}$.

$b=13.0976(5) \AA$

$\beta=89.0943(18)^{\circ}$.

$c=19.9752(7) \AA$

2503.64(16) $\AA^{3}$

2

$1.242 \mathrm{Mg} / \mathrm{m}^{3}$

$0.622 \mathrm{~mm}^{-1}$

992

APEX II Kappa Duo, Bruker

1.75 to $27.55^{\circ}$.

$-12 \leq h \leq 14,-17 \leq k \leq 16,-25 \leq l \leq 25$

38636

$11455[\mathrm{R}(\mathrm{int})=0.0523]$

8126

$99.2 \%$

Semi-empirical from equivalents

0.9577 and 0.8500

Intrinsic methods

Full-matrix least-squares on $\mathrm{F}^{2}$

$\mathrm{w}=\left[\sigma^{2} \mathrm{Fo}^{2}+\mathrm{AP}^{2}+\mathrm{BP}^{-1}\right.$, with

$\mathrm{P}=\left(\mathrm{Fo}^{2}+2 \mathrm{Fc}^{2}\right) / 3, \mathrm{~A}=0.0366, \mathrm{~B}=0.2311$

11455 / 0 / 597

1.035

$\mathrm{R} 1=0.0412, \mathrm{wR} 2=0.0857$

$\mathrm{R} 1=0.0713, \mathrm{wR} 2=0.0942$

0.340 and -0.411 e. $\AA^{-3}$ 
Table S11. Edited Ligfield output for square planar $(S=1) \mathrm{Fe}(2)$ site.

These matrices were generated from the following terms: 5D 3P1 3P2 3D 3F1 3F2 3G 3H 1S1 1S2 1D1 1D2 1F 1 G1 1 G2 1I of d6 in SLMSML-basis.

One electron parametrization was taken from: AOM. The AOM-parametrization were based on the following premisses: Maximum lambda $(\sigma, \pi, \delta, \phi)$ value included: $\sigma$. The AOM-matrices were not barycentered.

\begin{tabular}{l|l|l|l|l|} 
L Ligator & Theta & Phi & Psi & Linear \\
\hline IC & 90.000000 & 136.430000 & 0.000000 & Yes | \\
IC & 90.000000 & $\mid 223.570000$ & 0.000000 & Yes | \\
|H & 90.000000 & 42.440000 & 0.000000 & Yes | \\
|H' & 90.000000 & -42.440000 & 0.000000 & Yes \\
\hline
\end{tabular}

$\perp$ Parameter: $\mid$ Value: $\left(\mathrm{cm}^{-1}\right) \mid$

le $\sigma(C) \quad|6550.00000000|$

le $\sigma\left(C^{\prime}\right) \quad|6550.00000000|$

$|e \sigma(H) \quad| 5900.00000000 \mid$

|e $\sigma\left(H^{\prime}\right) \quad \mid 5900.00000000$ |

|Racah B | 700.00000000 |

|Racah C | 3100.00000000 |

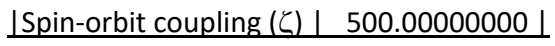

Eigenvalues (in $\mathrm{cm}^{-1}$ ) and eigenfunction labelling

Function: 1 ; Energy: 0.00000000

Spin labels: $(2 S+1)=3.42151$

Symmetry of eigenfunction: $A 1(D 2 *) \quad A 1(C 2 *)$

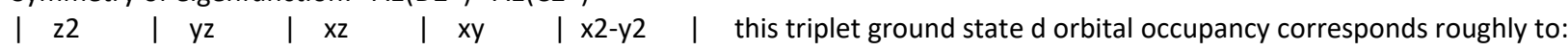
$|0.982339| 1.083510|1.901546| 0.292500|1.740105| \quad \mathrm{d}_{\mathrm{xz}-\mathrm{yz}}{ }^{2} \mathrm{~d}_{\mathrm{xz}}{ }^{2} \mathrm{~d}_{\mathrm{yz}}{ }^{1} \mathrm{~d}_{\mathrm{zz}}{ }^{1} \mathrm{~d}_{\mathrm{xy}}{ }^{0}$

Function: 2 ; Energy: 1.38419161

Spin labels: $(2 \mathrm{~S}+1)=3.66758$

Symmetry of eigenfunction: $B 1(D 2 *) \quad A 1(C 2 *)$

\begin{tabular}{l|l|l|l|l|l}
$z 2$ & $y z$ & $x z$ & $\mid x y$ & $x 2-y 2$ & similar to the above
\end{tabular}

\begin{tabular}{|l|l|l|l|l|l|}
1.023139 & $1.237170 \mid$ & 1.748155 & $0.365154 \mid$ & $1.626382 \mid$ \\
\hline
\end{tabular}

Function: 111 ; Energy: 57.78776185

Spin labels: $(2 S+1)=3.66005$

Symmetry of eigenfunction: $B 2\left(D 2^{*}\right) \quad B 1(C 2 *)$

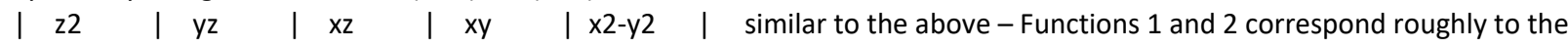

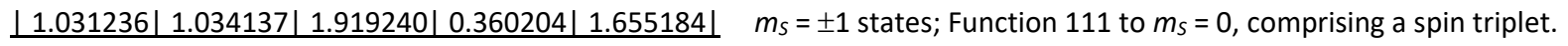

Function: 3 ; Energy: 304.19294837

Spin labels: $(2 \mathrm{~S}+1)=3.88596$

Symmetry of eigenfunction: $A 1(D 2 *) A 1(C 2 *)$

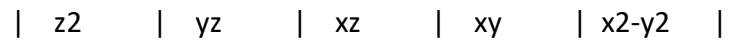

$|0.940837| 1.861203|1.110591| 0.535808|1.551561|$

Function: 112 ; Energy: 367.83549333

Spin labels: $(2 S+1)=4.15670$

Symmetry of eigenfunction: $B 3\left(D 2^{*}\right) \quad B 1(C 2 *)$

\begin{tabular}{|l|l|l|l|l|l|l|l|l|}
$z 2$ & $y z$ & $x z$ & $x y$ & $x 2-y 2$ & $\mid$
\end{tabular}

\begin{tabular}{|l|l|l|l|l|l|}
\hline 1.007055 & 1.962117 & 1.033967 & 0.598797 & 1.398065 \\
\hline
\end{tabular}

Function: 113 ; Energy: 456.58932190

Spin labels: $(2 S+1)=4.97532$

Symmetry of eigenfunction: B3(D2*) B1(C2*)

\begin{tabular}{|l|l|l|l|l|l|l|l|l|}
$z 2$ & $y z$ & $x z$ & $x y$ & $x$
\end{tabular}

\begin{tabular}{|l|l|l|l|l|l|}
\hline 1.005983 & 1.408983 & 1.279638 & 0.990553 & 1.314843 \\
\hline
\end{tabular}

Function: 114 ; Energy: 484.78557144

Spin labels: $(2 \mathrm{~S}+1)=4.98387$

Symmetry of eigenfunction: B2(D2*) B1(C2*)

\begin{tabular}{|l|l|l|l|l|l|l|l|}
$z 2$ & $y z$ & $x z$ & $x y$ & $x 2-y 2$
\end{tabular}

\begin{tabular}{|l|l|l|l|l|}
\hline 1.002029 & 1.349152 & 1.420455 & 0.993940 & 1.234423 \\
\hline
\end{tabular}

Function: 4 ; Energy: 527.32627346

Spin labels: $(2 \mathrm{~S}+1)=4.12032$

Symmetry of eigenfunction: $B 1(D 2 *) A 1(C 2 *)$ 
\begin{tabular}{|l|l|l|l|l|l|l|}
$z 2$ & $y z$ & $x z$ & $x y$ & $x 2-y 2$
\end{tabular}

\begin{tabular}{|l|l|l|l|l|l|}
\hline 1.005401 & 1.596765 & 1.142132 & 0.582370 & 1.673332 \\
\hline
\end{tabular}

Function: 5 ; Energy: 594.14636335

Spin labels: $(2 \mathrm{~S}+1)=4.56419$

Symmetry of eigenfunction: $A 1(D 2 *) \quad A 1(C 2 *)$

\begin{tabular}{|l|l|l|l|l|l|}
$z 2$ & $y z$ & $x z$ & $x y$ & $x 2-y 2$
\end{tabular}

\begin{tabular}{|l|l|l|l|l|}
$\mid 1.000324$ & 1.256579 & 1.075980 & 0.806174 & 1.860943 \\
\hline
\end{tabular}

Function: 6 ; Energy: 723.96162428

Spin labels: $(2 \mathrm{~S}+1)=4.94969$

Symmetry of eigenfunction: $A 1\left(D 2^{*}\right) A 1(C 2 *)$

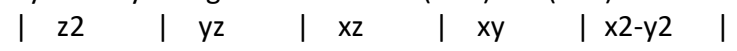

\begin{tabular}{|l|l|l|l|l|}
\hline $1.003160 \mid$ & 1.121806 & 1.318561 & 0.980400 & 1.576073 \\
\hline
\end{tabular}

Function: 7 ; Energy: 739.40342966

Spin labels: $(2 \mathrm{~S}+1)=4.96981$

Symmetry of eigenfunction: $B 1\left(D 2^{*}\right) \quad A 1(C 2 *)$

\begin{tabular}{|l|l|l|l|l|l|l|l|l|}
$z 2$ & $y z$ & $x z$ & $x y$ & $x 2-y 2$ & $\mid$
\end{tabular}

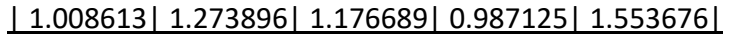

Function: 115 ; Energy: 812.99596793

Spin labels: $(2 \mathrm{~S}+1)=4.76483$

Symmetry of eigenfunction: B3(D2*) B1(C2*)

\begin{tabular}{|l|l|l|l|l|l|l|}
$z 2$ & $y z$ & $x z$ & $x y$ & $x 2-y 2$
\end{tabular}

\begin{tabular}{|l|l|l|l|l|}
$\mid 1.007636$ & 1.253141 & 1.259331 & 0.890943 & $1.588948 \mid$ \\
\hline
\end{tabular}

Function: 116 ; Energy: 816.69371585

Spin labels: $(2 S+1)=4.90639$

Symmetry of eigenfunction: B2(D2*) B1(C2*)

\begin{tabular}{|l|l|l|l|l|}
$z 2$ & $y z$ & $x z$ & $x y$ & $x 2-y 2$
\end{tabular}

\begin{tabular}{|l|l|l|l|l|}
\hline 1.004226 & 1.134572 & 1.402737 & 0.957346 & $1.501118 \mid$ \\
\hline
\end{tabular}

Function: 117 ; Energy: 1077.14761187

Spin labels: $(2 \mathrm{~S}+1)=4.97721$

Symmetry of eigenfunction: $B 2(D 2 *) \quad B 1(C 2 *)$

\begin{tabular}{|l|l|l|l|l|}
$\mathrm{z} 2$ & $\mathrm{yz}$ & $\mathrm{xz}$ & $\mathrm{xy}$ & $\mathrm{x} 2-\mathrm{y} 2$
\end{tabular}

\begin{tabular}{|l|l|l|l|l|}
1.001042 & 1.483995 & 1.513691 & 0.992712 & $1.008559 \mid$ \\
\hline
\end{tabular}

Function: 118 ; Energy: 1087.57000031

Spin labels: $(2 \mathrm{~S}+1)=4.99274$

Symmetry of eigenfunction: $B 3\left(D 2^{*}\right) \quad B 1\left(C 2^{*}\right)$

$\begin{array}{lllllll}\mathrm{z} 2 & \mathrm{y} & \mathrm{y} & \mathrm{xz} & \mathrm{x} y & \mathrm{x} 2-\mathrm{y} 2\end{array}$

\begin{tabular}{|l|l|l|l|l|l|}
\hline & 0.998858 & 1.536260 & 1.450375 & 0.999671 & 1.014836 \\
\hline
\end{tabular}

Function: 8 ; Energy: 1100.26176613

Spin labels: $(2 \mathrm{~S}+1)=4.28758$

Symmetry of eigenfunction: $B 1(D 2 *) \quad A 1(C 2 *)$

\begin{tabular}{|l|l|l|l|l|l|}
$\mid$ & $z 2$ & $y z$ & $x z$ & $x y$ & $\mid x 2-y 2$
\end{tabular}

\begin{tabular}{|l|l|l|l|l|l|}
\hline 1.010261 & 1.272156 & 1.709537 & 0.663679 & 1.344367 \\
\hline
\end{tabular}

Function: 9 ; Energy: 1284.77748532

Spin labels: $(2 \mathrm{~S}+1)=4.31634$

Symmetry of eigenfunction: $A 1(D 2 *) A 1(C 2 *)$

\begin{tabular}{|l|l|l|l|l|l|}
$\mid$ & $z 2$ & $y z$ & $x z$ & $x y$ & $\mid x 2-y 2$
\end{tabular}

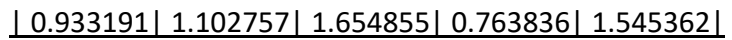

Function: 119 ; Energy: 1416.72745492

Spin labels: $(2 \mathrm{~S}+1)=4.43632$

Symmetry of eigenfunction: B2(D2*) B1(C2*)

\begin{tabular}{|l|l|l|l|l|}
$z 2$ & $y z$ & $x z$ & $x y$ & $x 2-y 2$
\end{tabular}

\begin{tabular}{|l|l|l|l|l|l|}
\hline 1.023703 & 1.031505 & 1.699461 & 0.732690 & 1.512640 \\
\hline
\end{tabular}

Function: 10 ; Energy: 1455.33438625

Spin labels: $(2 \mathrm{~S}+1)=4.06939$

Symmetry of eigenfunction: $A 1(D 2 *) \quad A 1(C 2 *)$

\begin{tabular}{|l|l|l|l|l|l|}
$z 2$ & $y z$ & $x z$ & $x y$ & $x 2-y 2$
\end{tabular}

\begin{tabular}{|l|l|l|l|l|l|}
\hline 0.895675 & 1.668319 & 1.149080 & 0.668966 & 1.617960 \\
\hline
\end{tabular} 
Function: 120 ; Energy: 1669.14400761

Spin labels: $(2 S+1)=4.07231$

Symmetry of eigenfunction: $B 3(D 2 *) \quad B 1(C 2 *)$

\begin{tabular}{|l|l|l|l|l|l|l|}
$\mathrm{z} 2$ & $\mathrm{yz}$ & $\mathrm{xz}$ & $\mathrm{xy}$ & $\mathrm{x} 2-\mathrm{y} 2$
\end{tabular}

\begin{tabular}{|l|l|l|l|l|l|}
\hline 1.009625 & 1.790338 & 1.015978 & 0.561104 & 1.622955 \\
\hline
\end{tabular}

Function: 11 ; Energy: 1738.12479426

Spin labels: $(2 \mathrm{~S}+1)=3.92840$

Symmetry of eigenfunction: $B 1(D 2 *) \quad A 1(C 2 *)$

\begin{tabular}{|l|l|l|l|l}
$z 2$ & $y z$ & $x z$ & $x y$ & $x 2-y 2$
\end{tabular}

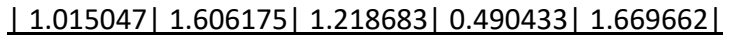

Function: 12 ; Energy: 2487.86507833

Spin labels: $(2 \mathrm{~S}+1)=1.78110$

Symmetry of eigenfunction: $A 1(D 2 *) \quad A 1(C 2 *)$

\begin{tabular}{|l|l|l|l|l|l|}
$z 2$ & $y z$ & $x z$ & $x y$ & $x 2-y 2$
\end{tabular}

\begin{tabular}{|l|l|l|l|l|l|}
\hline 0.415231 & 1.839128 & 1.736281 & 0.077952 & 1.931408 \\
\hline
\end{tabular}

Function: 121 ; Energy: 4449.98640421

Spin labels: $(2 \mathrm{~S}+1)=3.00255$

Symmetry of eigenfunction: B3(D2*) B1(C2*)

\begin{tabular}{lllll|l|l|l|l|}
$z 2$ & $y z$ & $x z$ & $x y$ & $\mid x 2-y 2$
\end{tabular} \mid

\begin{tabular}{|l|l|l|l|l|}
\hline 1.000968 & 1.902647 & 1.900639 & 0.113909 & 1.081836 \\
\hline
\end{tabular}

Function: 122 ; Energy: 4459.79983568

Spin labels: $(2 \mathrm{~S}+1)=3.00675$

Symmetry of eigenfunction: $B 2(D 2 *) \quad B 1(C 2 *)$

\begin{tabular}{|l|l|l|l|l}
$z 2$ & $y z$ & $x z$ & $x y$ & $x 2-y 2$
\end{tabular}

\begin{tabular}{|l|l|l|l|l|}
\hline 1.000519 & 1.901914 & 1.904407 & 0.113777 & 1.079382 \\
\hline
\end{tabular}

Function: 13 ; Energy: 4487.96173672

Spin labels: $(2 S+1)=3.01279$

Symmetry of eigenfunction: $B 1(D 2 *) \quad A 1(C 2 *)$

\begin{tabular}{|l|ll|lll|l}
$\mid$ & $z 2$ & $y z$ & $x z$ & $x y$ & $\mid x 2-y 2$
\end{tabular}

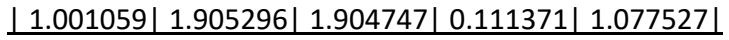

Function: 123 ; Energy: 6480.56324261

Spin labels: $(2 \mathrm{~S}+1)=3.49136$

Symmetry of eigenfunction: B3(D2*) B1(C2*)

\begin{tabular}{|l|l|l|l|l|l|l|}
$\mathrm{z} 2$ & $\mathrm{yz}$ & $\mathrm{xz}$ & $\mathrm{xy}$ & $\mathrm{x} 2-\mathrm{y} 2$
\end{tabular}

\begin{tabular}{|l|l|l|l|l|l|}
\hline 1.901150 & 1.010953 & 1.046885 & 0.339257 & 1.701755 \\
\hline
\end{tabular}

Function: 124 ; Energy: 6495.49294703

Spin labels: $(2 \mathrm{~S}+1)=3.54305$

Symmetry of eigenfunction: $B 2(D 2 *) \quad B 1(C 2 *)$

\begin{tabular}{|l|l|l|l|l|l}
$z 2$ & $y z$ & $x z$ & $x y$ & $x 2-y 2$
\end{tabular}

\begin{tabular}{|l|l|l|l|l|}
1.916836 & 1.034341 & 1.007906 & 0.350466 & $1.690451 \mid$ \\
\hline
\end{tabular}

Function: 14 ; Energy: 6502.91134124

Spin labels: $(2 \mathrm{~S}+1)=3.74938$

Symmetry of eigenfunction: $A 1\left(D 2^{*}\right) \quad A 1(C 2 *)$

\begin{tabular}{|l|l|l|l|l|l|}
$z 2$ & $y z$ & $x z$ & $x y$ & $x 2-y 2$
\end{tabular}

\begin{tabular}{|l|l|l|l|l|}
$\mid 1.949409$ & 1.006505 & 1.005351 & 0.415640 & 1.623095 \\
\hline
\end{tabular}

Function: 15 ; Energy: 7165.51722946

Spin labels: $(2 \mathrm{~S}+1)=4.98874$

Symmetry of eigenfunction: $A 1\left(D 2^{*}\right) \quad A 1(C 2 *)$

\begin{tabular}{|l|l|l|l|l|l|l|}
$\mathrm{z} 2$ & $\mathrm{yz}$ & $\mathrm{xz}$ & $\mathrm{xy}$ & $\mathrm{x} 2-\mathrm{y} 2$ & |
\end{tabular}

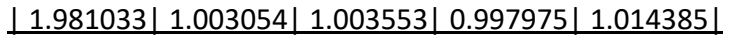

Function: 16 ; Energy: 7165.92117451

Spin labels: $(2 S+1)=4.98910$

Symmetry of eigenfunction: $B 1\left(D 2^{*}\right) \quad A 1(C 2 *)$

\begin{tabular}{|l|l|l|l|l|}
\hline$z 2$ & $y z$ & $x z$ & $x y$ & $x 2-y 2$
\end{tabular} \mid

\begin{tabular}{|l|l|l|l|l|}
\hline 1.981095 & 1.002972 & 1.003476 & 0.998078 & $1.014379 \mid$ \\
\hline
\end{tabular} 
Function: 125 ; Energy: 7480.43269793

Spin labels: $(2 S+1)=4.18810$

Symmetry of eigenfunction: B3(D2*) B1(C2*)

\begin{tabular}{|l|l|l|l|l|}
$\mid z 2$ & $y z$ & $x z$ & $x y$ & $x 2-y 2$
\end{tabular}

\begin{tabular}{|l|l|l|l|l|}
\hline 1.878422 & 1.010287 & 1.086487 & 0.709212 & $1.315591 \mid$ \\
\hline
\end{tabular}

Function: 126 ; Energy: 7504.52700799

Spin labels: $(2 \mathrm{~S}+1)=4.25566$

Symmetry of eigenfunction: B2(D2*) B1(C2*)

\begin{tabular}{|l|l|l|l|l|l|}
$\mathrm{z} 2$ & $\mathrm{yz}$ & $\mathrm{xz}$ & $\mathrm{xy}$ & $\mathrm{x} 2-\mathrm{y} 2$ & |
\end{tabular}

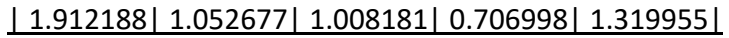

Function: 17 ; Energy: 7648.63496803

Spin labels: $(2 \mathrm{~S}+1)=4.24162$

Symmetry of eigenfunction: $A 1(D 2 *) \quad A 1(C 2 *)$

\begin{tabular}{|l|l|l|l|l|l|}
$\mathrm{z} 2$ & $\mathrm{yz}$ & $\mathrm{xz}$ & $\mathrm{xy}$ & $\mathrm{x} 2-\mathrm{y} 2$ & |
\end{tabular}

\begin{tabular}{|l|l|l|l|l|l|}
\hline 1.962408 & 1.004043 & 1.003698 & 0.650049 & 1.379802 \\
\hline
\end{tabular}

Function: 127 ; Energy: 8313.32034411

Spin labels: $(2 \mathrm{~S}+1)=1.35017$

Symmetry of eigenfunction: $B 3(D 2 *) \quad B 1(C 2 *)$

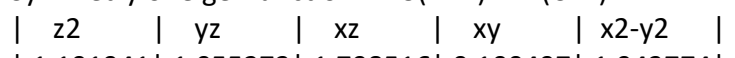

\begin{tabular}{|l|l|l|l|l|}
$\mid 1.101941$ & 1.055273 & 1.798516 & 0.100497 & $1.943774 \mid$ \\
\hline
\end{tabular}

Function: 128 ; Energy: 8521.24049323

Spin labels: $(2 \mathrm{~S}+1)=1.22168$

Symmetry of eigenfunction: B2(D2*) B1(C2*)

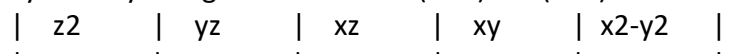

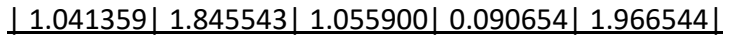

Function: 18 ; Energy: 11907.85815259

Spin labels: $(2 \mathrm{~S}+1)=2.99693$

Symmetry of eigenfunction: $A 1(D 2 *) \quad A 1(C 2 *)$

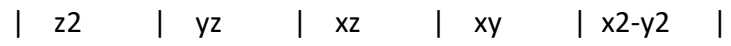

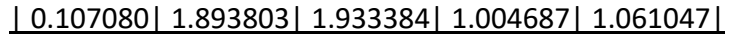

Function: 129 ; Energy: 11938.97756007

Spin labels: $(2 \mathrm{~S}+1)=3.00277$

Symmetry of eigenfunction: B3(D2*) B1(C2*)

\begin{tabular}{|l|l|l|l|l|l|l|}
$z 2$ & $y z$ & $x z$ & $x y$ & $x 2-y 2$ & |
\end{tabular}

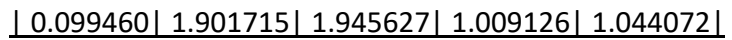

Function: 130 ; Energy: 11975.49622061

Spin labels: $(2 \mathrm{~S}+1)=3.00289$

Symmetry of eigenfunction: $B 2(D 2 *) \quad B 1(C 2 *)$

\begin{tabular}{|l|l|l|l|l|l}
$z 2$ & $y z$ & $x z$ & $x y$ & $x 2-y 2$
\end{tabular} \begin{tabular}{|l|l|l|l|l|l|}
\hline & 0.088765 & 1.944246 & 1.937611 & 1.010414 & $1.018964 \mid$ \\
\hline
\end{tabular}

Function: 19 ; Energy: 13157.06869326

Spin labels: $(2 \mathrm{~S}+1)=2.98940$

Symmetry of eigenfunction: $B 1\left(D 2^{*}\right) \quad A 1(C 2 *)$

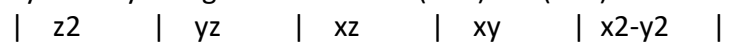

\begin{tabular}{|l|l|l|l|l|l|}
\hline 0.373255 & 1.033486 & 1.932596 & 0.994114 & 1.666549 \\
\hline
\end{tabular}

Function: 20 ; Energy: 13282.37225505

Spin labels: $(2 \mathrm{~S}+1)=2.98697$

Symmetry of eigenfunction: $A 1\left(D 2^{*}\right) \quad A 1(C 2 *)$

\begin{tabular}{|l|l|l|l|l|l|l|}
$\mathrm{z} 2$ & $\mathrm{yz}$ & $\mathrm{xz}$ & $\mathrm{x}$ & $\mathrm{x}$ & $\mathrm{x} 2-\mathrm{y}$ & |
\end{tabular}

\begin{tabular}{|l|l|l|l|l|}
\hline 0.366191 & 1.071998 & 1.949517 & 0.988342 & 1.623953 \\
\hline
\end{tabular}

Function: 131 ; Energy: 13300.39842281

Spin labels: $(2 S+1)=2.99294$

Symmetry of eigenfunction: B3(D2*) B1(C2*)

\begin{tabular}{|l|l|l|l|l|}
$z 2$ & $y z$ & $x z$ & $x y$ & $x 2-y 2$
\end{tabular}

\begin{tabular}{|l|l|l|l|l|}
\hline 0.369620 & 1.050438 & 1.952112 & 0.991357 & 1.636473 \\
\hline
\end{tabular} 
Function: 21 ; Energy: 13903.99100000

Spin labels: $(2 \mathrm{~S}+1)=2.59094$

Symmetry of eigenfunction: $A 1(D 2 *) \quad A 1(C 2 *)$

\begin{tabular}{|l|l|l|l|l|}
$\mid z 2$ & $y z$ & $x z$ & $x y$ & $x 2-y 2$
\end{tabular}

\begin{tabular}{|l|l|l|l|l|}
\hline 1.580201 & 1.616253 & 1.380954 & 0.320054 & 1.102537 \\
\hline
\end{tabular}

Function: 22 ; Energy: 14086.31190858

Spin labels: $(2 \mathrm{~S}+1)=2.95247$

Symmetry of eigenfunction: B1(D2*) $A 1(C 2 *)$

\begin{tabular}{|l|l|l|l|l|l|}
$\mathrm{z} 2$ & $\mathrm{yz}$ & $\mathrm{xz}$ & $\mathrm{xy}$ & $\mathrm{x} 2-\mathrm{y} 2$ & |
\end{tabular}

\begin{tabular}{|l|l|l|l|l|}
\hline 1.646331 & 1.627805 & 1.290098 & 0.378558 & 1.057208 \\
\hline
\end{tabular}

Function: 132 ; Energy: 14150.44982803

Spin labels: $(2 \mathrm{~S}+1)=3.00054$

Symmetry of eigenfunction: $B 3(D 2 *) \quad B 1(C 2 *)$

\begin{tabular}{|l|l|l|l|l|l|}
$z 2$ & $y z$ & $x z$ & $x y$ & $x 2-y 2$
\end{tabular}

\begin{tabular}{|l|l|l|l|l|l|}
1 & 1.646622 & 1.653179 & 1.284777 & 0.385637 & 1.029785 \\
\hline
\end{tabular}

Function: 23 ; Energy: 14197.94150851

Spin labels: $(2 \mathrm{~S}+1)=2.92389$

Symmetry of eigenfunction: $A 1\left(D 2^{*}\right) \quad A 1\left(C 2^{*}\right)$

\begin{tabular}{|l|l|l|l|l|l|}
$z z 2$ & $y z$ & $x z$ & $x y$ & $x 2-y 2$
\end{tabular}

\begin{tabular}{|l|l|l|l|l|l|}
$\mid 1.512014$ & 1.439943 & 1.527003 & 0.414940 & $1.106101 \mid$ \\
\hline
\end{tabular}

Function: 24 ; Energy: 14312.27375467

Spin labels: $(2 \mathrm{~S}+1)=2.92967$

Symmetry of eigenfunction: $B 1\left(D 2^{*}\right) \quad A 1(C 2 *)$

\begin{tabular}{|l|l|l|l|l|l|l|}
$z 2$ & $y z$ & $x z$ & $x y$ & $x 2-y 2$
\end{tabular}

\begin{tabular}{|l|l|l|l|l|}
\hline 1.457341 & 1.382630 & 1.538515 & 0.465077 & 1.156436 \\
\hline
\end{tabular}

Function: 133 ; Energy: 14337.27716871

Spin labels: $(2 \mathrm{~S}+1)=3.00112$

Symmetry of eigenfunction: $B 2(D 2 *) \quad B 1(C 2 *)$

\begin{tabular}{|l|l|l|l|l|l|l|}
$z 2$ & $y z$ & $x z$ & $x y$ & $x 2-y 2$
\end{tabular}

\begin{tabular}{|l|l|l|l|l|}
$\mid 1.291856$ & 1.465859 & 1.510616 & 0.530896 & 1.200773 \\
\hline
\end{tabular}

Function: 25 ; Energy: 14431.84781289

Spin labels: $(2 \mathrm{~S}+1)=2.97399$

Symmetry of eigenfunction: $B 1\left(D 2^{*}\right) \quad A 1(C 2 *)$

\begin{tabular}{|l|l|l|l|l|l|l|}
$z 2$ & $y z$ & $x z$ & $x y$ & $x 2-y 2$ & |
\end{tabular}

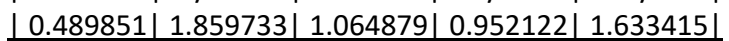

Function: 26 ; Energy: 14485.60726136

Spin labels: $(2 \mathrm{~S}+1)=2.98479$

Symmetry of eigenfunction: $A 1(D 2 *) \quad A 1(C 2 *)$

\begin{tabular}{|l|l|l|l|l|l|}
$z 2$ & $y z$ & $x z$ & $x y$ & $x 2-y 2$ & $\mid$
\end{tabular}

\begin{tabular}{|l|l|l|l|l|l|}
0.485661 & 1.874451 & 1.055851 & 0.952772 & 1.631265 \\
\hline
\end{tabular}

Function: 134 ; Energy: 14490.14555651

Spin labels: $(2 \mathrm{~S}+1)=2.99416$

Symmetry of eigenfunction: B2(D2*) B1(C2*)

\begin{tabular}{|l|l|l|l|l|l|l|}
$z 2$ & $y z$ & $x z$ & $x y$ & $x 2-y 2$
\end{tabular}

\begin{tabular}{|l|l|l|l|l|l|}
\hline 0.639419 & 1.804105 & 1.112659 & 0.892116 & $1.551701 \mid$ \\
\hline
\end{tabular}

Function: 27 ; Energy: 15305.03117760

Spin labels: $(2 \mathrm{~S}+1)=1.16424$

Symmetry of eigenfunction: $B 1\left(D 2^{*}\right) \quad A 1(C 2 *)$

\begin{tabular}{|l|l|l|l|l|l|l|}
$z 2$ & $y z$ & $x z$ & $x y$ & $x 2-y 2$
\end{tabular}

\begin{tabular}{|l|l|l|l|l|}
\hline 1.869296 & $1.047770 \mid$ & 1.040244 & 0.149647 & 1.893043 \\
\hline
\end{tabular}

Function: 28 ; Energy: 15395.63072072

Spin labels: $(2 S+1)=1.53992$

Symmetry of eigenfunction: $A 1\left(D 2^{*}\right) \quad A 1(C 2 *)$

\begin{tabular}{|l|l|l|l|l|l|l|}
$\mathrm{z} 2$ & $\mathrm{yz}$ & $\mathrm{xz}$ & $\mathrm{x} y$ & $\mathrm{x} 2-\mathrm{y} 2$ & |
\end{tabular}

\begin{tabular}{|l|l|l|l|l|}
\hline 1.256218 & 1.647229 & 1.640020 & 0.221548 & 1.234986 \\
\hline
\end{tabular} 
Function: 29 ; Energy: 16692.61490438

Spin labels: $(2 S+1)=1.07604$

Symmetry of eigenfunction: $A 1\left(D 2^{*}\right) \quad A 1\left(C 2^{*}\right)$

\begin{tabular}{l|l|l|l|l|l|l|l|}
$z z 2$ & $y z$ & $x z$ & $x y$ & $x 2-y 2$
\end{tabular}

\begin{tabular}{|l|l|l|l|l|}
\hline 1.615069 & 1.150305 & 1.190008 & 0.255428 & 1.789190 \\
\hline
\end{tabular}

Function: 30 ; Energy: 17496.97480384

start - transitions contributing to observed Vis band

Spin labels: $(2 \mathrm{~S}+1)=2.98285$

Symmetry of eigenfunction: $B 1(D 2 *) \quad A 1(C 2 *)$

\begin{tabular}{|l|l|l|l|l|l|l|}
$\mathrm{z} 2$ & $\mathrm{yz}$ & $\mathrm{xz}$ & $\mathrm{x} y$ & $\mathrm{x} 2-\mathrm{y} 2$
\end{tabular}

\begin{tabular}{|l|l|l|l|l|l|l|}
1 & 1.044213 & 1.107438 & 1.313893 & 0.979323 & 1.555133 \\
\hline
\end{tabular}

Function: 135 ; Energy: 17516.56079050

Spin labels: $(2 S+1)=2.99797$

Symmetry of eigenfunction: $B 3(D 2 *) \quad B 1(C 2 *)$

\begin{tabular}{|l|l|l|l|l|l}
$z 2$ & $y z$ & $x z$ & $x y$ & $x 2-y 2$
\end{tabular}

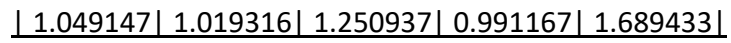

Function: 136 ; Energy: 17550.94295643

Spin labels: $(2 \mathrm{~S}+1)=2.99877$

Symmetry of eigenfunction: $B 2(D 2 *) \quad B 1(C 2 *)$

\begin{tabular}{|l|l|l|l|l|l|}
$\mathrm{z} 2$ & $\mathrm{yz}$ & $\mathrm{xz}$ & $\mathrm{xy}$ & $\mathrm{x} 2-\mathrm{y} 2$
\end{tabular}

\begin{tabular}{|l|l|l|l|l|l|}
1 & 1.044030 & 1.153613 & 1.027100 & 0.987376 & $1.787881 \mid$ \\
\hline
\end{tabular}

Function: 31 ; Energy: 17598.44920010

Spin labels: $(2 \mathrm{~S}+1)=2.63097$

Symmetry of eigenfunction: $B 1\left(D 2^{*}\right) \quad A 1(C 2 *)$

\begin{tabular}{|l|l|l|l|l|l|l|}
$z 2$ & $y z$ & $x z$ & $x y$ & $x 2-y 2$
\end{tabular}

\begin{tabular}{|l|l|l|l|l|}
\hline 0.846813 & 1.496210 & 1.565412 & 1.002370 & 1.089195 \\
\hline
\end{tabular}

Function: 32 ; Energy: 17795.72762619

Spin labels: $(2 \mathrm{~S}+1)=2.98755$

Symmetry of eigenfunction: $A 1(D 2 *) \quad A 1(C 2 *)$

\begin{tabular}{|l|l|l|l|l|l|l|} 
z 2 & $y z$ & $x z$ & $x y$ & $x 2-y 2$
\end{tabular}

\begin{tabular}{|l|l|l|l|l|l|}
\hline 1.044824 & 1.083489 & 1.880740 & 0.987420 & $1.003528 \mid$ \\
\hline
\end{tabular}

Function: 137 ; Energy: 17870.18567385

Spin labels: $(2 \mathrm{~S}+1)=2.99841$

Symmetry of eigenfunction: B3(D2*) B1(C2*)

\begin{tabular}{|l|l|l|l|l|l|l|}
$z 2$ & $y z$ & $x z$ & $x y$ & $x 2-y 2$ & $\mid$
\end{tabular} \begin{tabular}{|l|l|l|l|l|l|}
1 & 1.049108 & 1.050363 & 1.666589 & 0.999789 & $1.234151 \mid$ \\
\hline
\end{tabular}

Function: 33 ; Energy: 18049.36679014

Spin labels: $(2 \mathrm{~S}+1)=3.01046$

Symmetry of eigenfunction: $A 1(D 2 *) \quad A 1(C 2 *)$

\begin{tabular}{|l|l|l|l|l|l}
$z 2$ & $y z$ & $x z$ & $x y$ & $x 2-y 2$
\end{tabular}

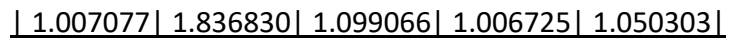

Function: 34 ; Energy: 18052.58333962

Spin labels: $(2 \mathrm{~S}+1)=2.95065$

Symmetry of eigenfunction: $B 1\left(D 2^{*}\right) \quad A 1(C 2 *)$

\begin{tabular}{|l|l|l|l|l|l|l|}
$z 2$ & $y z$ & $x z$ & $x y$ & $x 2-y 2$
\end{tabular}

\begin{tabular}{|l|l|l|l|l|}
$\mid 1.031654$ & 1.432097 & 1.259834 & 0.979945 & $1.296470 \mid$ \\
\hline
\end{tabular}

Function: 138 ; Energy: 18109.29725947

Spin labels: $(2 S+1)=3.01253$

Symmetry of eigenfunction: $B 2(D 2 *) \quad B 1(C 2 *)$

\begin{tabular}{|l|l|l|l|l|l|}
$\mathrm{z} 2$ & $\mathrm{yz}$ & $\mathrm{xz}$ & $\mathrm{xy}$ & $\mathrm{x} 2-\mathrm{y} 2$
\end{tabular}

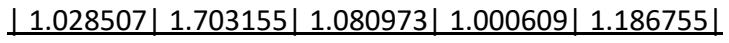

Function: 35 ; Energy: 18313.59063506

Spin labels: $(2 \mathrm{~S}+1)=2.97043$

Symmetry of eigenfunction: $A 1\left(D 2^{*}\right) \quad A 1\left(C 2^{*}\right)$

\begin{tabular}{|l|l|l|l|l|}
$z 2$ & $y z$ & $x z$ & $x y$ & $x 2-y 2$
\end{tabular}

\begin{tabular}{|l|l|l|l|l|l|l|}
\hline 1.134705 & 0.659689 & 1.449811 & 0.975325 & $1.780470 \mid$ \\
\hline
\end{tabular} 
Function: 139 ; Energy: 18327.60414397

Spin labels: $(2 S+1)=2.99822$

Symmetry of eigenfunction: B2(D2*) B1(C2*)

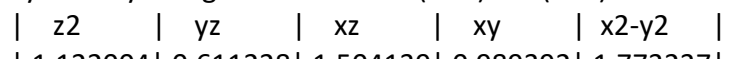

\begin{tabular}{|l|l|l|l|l|}
\hline 1.122004 & 0.611228 & 1.504139 & 0.989392 & 1.773237 \\
\hline
\end{tabular}

Function: 140 ; Energy: 18331.08187737

end - transitions contributing to observed Vis band

Spin labels: $(2 S+1)=3.00009$

Symmetry of eigenfunction: B3(D2*) B1(C2*)

\begin{tabular}{|l|l|l|l|l|l|l|}
$z 2$ & $y z$ & $x z$ & $x y$ & $x 2-y 2$ & |
\end{tabular}

\begin{tabular}{|l|l|l|l|l|l|}
\hline 1.125904 & 0.593598 & 1.489629 & 0.988684 & 1.802186 \\
\hline
\end{tabular}

Function: 36 ; Energy: 19040.02193280

Spin labels: $(2 \mathrm{~S}+1)=1.53320$

Symmetry of eigenfunction: $B 1\left(D 2^{*}\right) \quad A 1(C 2 *)$

\begin{tabular}{|l|l|l|l|l|l|l|l|l|}
$z 2$ & $y z$ & $x z$ & $x y$ & $x$
\end{tabular}

\begin{tabular}{|l|l|l|l|l|l|}
\hline & 0.298002 & 1.865639 & 1.795863 & 1.019121 & $1.021374 \mid$ \\
\hline
\end{tabular}

Function: 141 ; Energy: 19324.26041913

Spin labels: $(2 \mathrm{~S}+1)=4.50687$

Symmetry of eigenfunction: B3(D2*) B1(C2*)

\begin{tabular}{|l|l|l|l|l|l|l|l|l|}
$z 2$ & $y z$ & $x z$ & $x y$ & |
\end{tabular}

\begin{tabular}{|l|l|l|l|l|l|}
\hline 1.025340 & 1.038623 & 1.010955 & 1.757715 & $1.167368 \mid$ \\
\hline
\end{tabular}

Function: 37 ; Energy: 19327.03304947

Spin labels: $(2 S+1)=4.67299$

Symmetry of eigenfunction: $B 1\left(D 2^{*}\right) \quad A 1(C 2 *)$

\begin{tabular}{|l|l|l|l|l|l|}
$\mathrm{z} 2$ & $\mathrm{yz}$ & $\mathrm{xz}$ & $\mathrm{x} y$ & $\mathrm{x} 2-\mathrm{y} 2$ & |
\end{tabular}

\begin{tabular}{|l|l|l|l|l|}
\hline 1.016068 & 1.003338 & 1.020120 & 1.840457 & 1.120017 \\
\hline
\end{tabular}

Function: 142 ; Energy: 19332.02349757

Spin labels: $(2 S+1)=4.45709$

Symmetry of eigenfunction: B2(D2*) B1(C2*)

\begin{tabular}{|l|l|l|l|l|l|l|} 
z 2 & $y z$ & $x z$ & $x y$ & $x 2-y 2$
\end{tabular}

\begin{tabular}{|l|l|l|l|l|}
\hline 1.028215 & 1.040905 & 1.014381 & 1.736413 & 1.180086 \\
\hline
\end{tabular}

Function: 38 ; Energy: 19372.89716888

Spin labels: $(2 \mathrm{~S}+1)=4.84446$

Symmetry of eigenfunction: $B 1(D 2 *) \quad A 1(C 2 *)$

\begin{tabular}{|l|l|l|l|l|l|l|}
$z 2$ & $y z$ & $x z$ & $x y$ & $x 2-y 2$ & |
\end{tabular} \begin{tabular}{|l|l|l|l|l|l|}
\hline 0.999784 & 1.038349 & 1.015270 & 1.924790 & 1.021807 \\
\hline
\end{tabular}

Function: 39 ; Energy: 19373.62793204

Spin labels: $(2 \mathrm{~S}+1)=4.83786$

Symmetry of eigenfunction: $A 1(D 2 *) \quad A 1(C 2 *)$

\begin{tabular}{|l|l|l|l|l|l}
$z 2$ & $y z$ & $x z$ & $x y$ & $x 2-y 2$
\end{tabular}

\begin{tabular}{|l|l|l|l|l|}
\hline 1.003256 & 1.033388 & 1.036012 & 1.921727 & $1.005616 \mid$ \\
\hline
\end{tabular}

Function: 143 ; Energy: 19401.52050924

Spin labels: $(2 \mathrm{~S}+1)=3.21254$

Symmetry of eigenfunction: B2(D2*) B1(C2*)

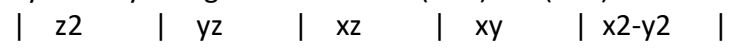

\begin{tabular}{|l|l|l|l|l|}
$\mid 1.073994$ & 1.101032 & 1.042355 & 1.133850 & $1.648769 \mid$ \\
\hline
\end{tabular}

Function: 144 ; Energy: 19445.53356224

Spin labels: $(2 \mathrm{~S}+1)=3.37067$

Symmetry of eigenfunction: B3(D2*) B1(C2*)

\begin{tabular}{|l|l|l|l|l|l|}
$z 2$ & $y z$ & $x z$ & $x y$ & $x 2-y 2$
\end{tabular}

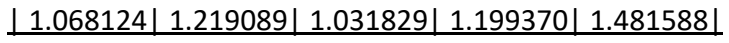

Function: 40 ; Energy: 19491.38261988

Spin labels: $(2 S+1)=3.24758$

Symmetry of eigenfunction: $B 1\left(D 2^{*}\right) \quad A 1(C 2 *)$

\begin{tabular}{|l|l|l|l|l|}
$z 2$ & $y z$ & $x z$ & $x y$ & $x 2-y 2$
\end{tabular}

\begin{tabular}{|l|l|l|l|l|}
\hline 1.080504 & 0.997556 & 1.011202 & 1.133903 & 1.776836 \\
\hline
\end{tabular} 
Function: 145 ; Energy: 19520.98644450

Spin labels: $(2 S+1)=2.99669$

Symmetry of eigenfunction: B3(D2*) B1(C2*)

\begin{tabular}{|l|l|l|l|l|}
$\mid z 2$ & $y z$ & $x z$ & $x y$ & $x 2-y 2$
\end{tabular}

\begin{tabular}{|l|l|l|l|l|}
\hline 1.075600 & 1.606753 & 1.130022 & 1.011910 & $1.175714 \mid$ \\
\hline
\end{tabular}

Function: 146 ; Energy: 19523.80074162

Spin labels: $(2 \mathrm{~S}+1)=3.15969$

Symmetry of eigenfunction: B2(D2*) B1(C2*)

\begin{tabular}{|l|l|l|l|l|l|} 
| z2 & $y z$ & $x z$ & $x y$ & $x 2-y 2$
\end{tabular}

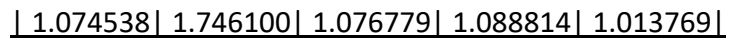

Function: 41 ; Energy: 19550.15046502

Spin labels: $(2 \mathrm{~S}+1)=2.98742$

Symmetry of eigenfunction: $A 1(D 2 *) A 1(C 2 *)$

\begin{tabular}{|l|l|l|l|l|l}
$z 2$ & $y z$ & $x z$ & $x y$ & $x 2-y 2$
\end{tabular}

\begin{tabular}{|l|l|l|l|l|l|}
\hline 1.083867 & 1.804573 & 1.169495 & 1.006030 & 0.936035 \\
\hline
\end{tabular}

Function: 42 ; Energy: 20008.52381997

Spin labels: $(2 \mathrm{~S}+1)=1.69913$

Symmetry of eigenfunction: $A 1\left(D 2^{*}\right) \quad A 1\left(C 2^{*}\right)$

\begin{tabular}{|l|l|l|l|l|l|l|l|l|l|}
$z 2$ & $y z$ & $x z$ & $x y$ & $x 2-y 2$
\end{tabular}

\begin{tabular}{|l|l|l|l|l|l|}
\hline 1.456955 & 1.267922 & 1.037747 & 0.564126 & $1.673250 \mid$ \\
\hline
\end{tabular}

Function: 147 ; Energy: 20124.21858356

Spin labels: $(2 \mathrm{~S}+1)=3.00118$

Symmetry of eigenfunction: $B 2(D 2 *) \quad B 1(C 2 *)$

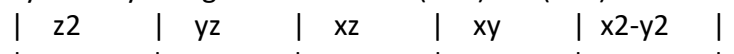

\begin{tabular}{|l|l|l|l|l|}
\hline 1.031112 & 1.670012 & 1.077245 & 0.969647 & 1.251984 \\
\hline
\end{tabular}

Function: 43 ; Energy: 20149.43061127

Spin labels: $(2 \mathrm{~S}+1)=3.00453$

Symmetry of eigenfunction: $B 1(D 2 *) \quad A 1(C 2 *)$

| z2 | yz | xz | xy | x2-y2 |

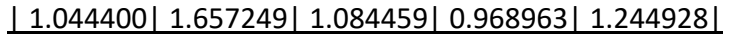

Function: 44 ; Energy: 20253.52386160

Spin labels: $(2 \mathrm{~S}+1)=2.42881$

Symmetry of eigenfunction: $A 1(D 2 *) A 1(C 2 *)$

\begin{tabular}{|l|l|l|l|l|l|l|}
$z 2$ & $y z$ & $x z$ & $x y$ & $x 2-y 2$ & |
\end{tabular}

\begin{tabular}{|l|l|l|l|l|}
$\mid 1.220669$ & 1.514087 & 1.088398 & 0.769950 & 1.406896 \\
\hline
\end{tabular}

Function: 148 ; Energy: 20645.50822528

Spin labels: $(2 \mathrm{~S}+1)=3.00622$

Symmetry of eigenfunction: $B 3(D 2 *) \quad B 1(C 2 *)$

\begin{tabular}{|l|l|l|l|l|l}
$z 2$ & $y z$ & $x z$ & $x y$ & $x 2-y 2$
\end{tabular}

\begin{tabular}{|l|l|l|l|l|}
$\mid 1.008066$ & 1.074239 & 1.679574 & 0.959998 & $1.278122 \mid$ \\
\hline
\end{tabular}

Function: 45 ; Energy: 20687.96999142

Spin labels: $(2 \mathrm{~S}+1)=3.00781$

Symmetry of eigenfunction: $B 1\left(D 2^{*}\right) \quad A 1(C 2 *)$

\begin{tabular}{|l|l|l|l|l|l|l|}
$z$ & $z 2$ & $y z$ & $x z$ & $x y$ & $x 2-y 2$
\end{tabular}

\begin{tabular}{|l|l|l|l|l|}
\hline & 0.995988 & 1.076907 & 1.684987 & 0.963801 \\
\hline
\end{tabular}

Function: 46 ; Energy: 20710.96768223

Spin labels: $(2 \mathrm{~S}+1)=2.95626$

Symmetry of eigenfunction: $A 1(D 2 *) \quad A 1(C 2 *)$

\begin{tabular}{|l|l|l|l|l|l|l|}
$\mathrm{z} 2$ & $\mathrm{yz}$ & $\mathrm{xz}$ & $\mathrm{xy}$ & $\mathrm{x} 2-\mathrm{y} 2$ & |
\end{tabular}

\begin{tabular}{|l|l|l|l|l|}
\hline 1.019397 & 1.084232 & 1.676610 & 0.937435 & 1.282326 \\
\hline
\end{tabular}

Function: 149 ; Energy: 21642.97092642

Spin labels: $(2 \mathrm{~S}+1)=1.14851$

Symmetry of eigenfunction: B2(D2*) B1(C2*)

\begin{tabular}{|l|l|l|l|l|}
$z 2$ & $y z$ & $x z$ & $x y$ & $x 2-y 2$
\end{tabular}

\begin{tabular}{|l|l|l|l|l|}
\hline 1.025240 & 1.275352 & 1.528028 & 0.762851 & $1.408529 \mid$ \\
\hline
\end{tabular} 
Function: 150 ; Energy: 21991.14415290

Spin labels: $(2 S+1)=2.63852$

Symmetry of eigenfunction: B3(D2*) B1(C2*)

\begin{tabular}{|l|l|l|l|l|l|l|} 
| z2 & $y z$ & $x z$ & $x y$ & $x 2-y 2$ & |
\end{tabular}

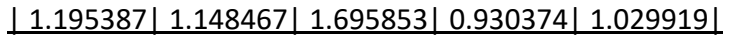

Function: 47 ; Energy: 22059.04892278

Spin labels: $(2 \mathrm{~S}+1)=3.02912$

Symmetry of eigenfunction: $B 1(D 2 *) \quad A 1(C 2 *)$

\begin{tabular}{|l|l|l|l|l|l}
$z 2$ & $y z$ & $x z$ & $x y$ & $x 2-y 2$
\end{tabular}

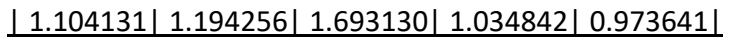

Function: 48 ; Energy: 22092.95685495

Spin labels: $(2 \mathrm{~S}+1)=3.01524$

Symmetry of eigenfunction: $A 1(D 2 *) A 1(C 2 *)$

\begin{tabular}{|l|l|l|l|l|l}
$z 2$ & $y z$ & $x z$ & $x y$ & $x 2-y 2$
\end{tabular}

\begin{tabular}{|l|l|l|l|l|l|}
\hline 1.093392 & 1.197552 & 1.712184 & 1.030412 & $0.966460 \mid$ \\
\hline
\end{tabular}

Function: 151 ; Energy: 22399.93397100

Spin labels: $(2 \mathrm{~S}+1)=1.85801$

Symmetry of eigenfunction: $B 3(D 2 *) \quad B 1(C 2 *)$

\begin{tabular}{|l|l|l|l|l|l|}
$z 2$ & $y z$ & $x z$ & $x y$ & $x 2-y 2$
\end{tabular}

\begin{tabular}{|l|l|l|l|l|}
\hline 1.146047 & 1.287252 & 1.379595 & 0.802249 & $1.384857 \mid$ \\
\hline
\end{tabular}

Function: 152 ; Energy: 22432.29513440

Spin labels: $(2 \mathrm{~S}+1)=2.90537$

Symmetry of eigenfunction: $B 2(D 2 *) \quad B 1(C 2 *)$

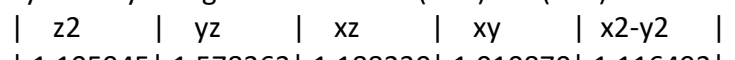

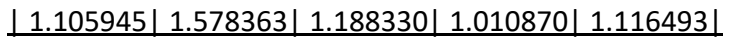

Function: 49 ; Energy: 22530.39709313

Spin labels: $(2 S+1)=3.04697$

Symmetry of eigenfunction: $B 1(D 2 *) \quad A 1(C 2 *)$

\begin{tabular}{|l|l|l|l|l|l|l|}
$z 2$ & $y z$ & $x z$ & $x y$ & $x 2-y 2$
\end{tabular}

\begin{tabular}{|l|l|l|l|l|l|}
\hline 1.077903 & 1.561815 & 1.213410 & 1.043530 & $1.103342 \mid$ \\
\hline
\end{tabular}

Function: 50 ; Energy: 22572.93556753

Spin labels: $(2 \mathrm{~S}+1)=3.03450$

Symmetry of eigenfunction: $A 1(D 2 *) A 1(C 2 *)$

\begin{tabular}{|l|l|l|l|l|l|l|}
$z 2$ & $y z$ & $x z$ & $x y$ & $x 2-y 2$ & |
\end{tabular} \begin{tabular}{|l|l|l|l|l|l|}
\hline 1.053468 & 1.672177 & 1.233532 & 1.040882 & $0.999940 \mid$ \\
\hline
\end{tabular}

Function: 153 ; Energy: 22777.08352188

Spin labels: $(2 \mathrm{~S}+1)=2.59044$

Symmetry of eigenfunction: B3(D2*) B1(C2*)

\begin{tabular}{|l|l|l|l|l|l|l|l|}
$z 2$ & $y z$ & $x z$ & $x y$ & $x 2-y 2$ & $\mid$
\end{tabular}

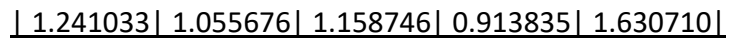

Function: 154 ; Energy: 22784.17938108

Spin labels: $(2 \mathrm{~S}+1)=2.90104$

Symmetry of eigenfunction: B2(D2*) B1(C2*)

\begin{tabular}{|l|l|l|l|l|l}
$z 2$ & $y z$ & $x z$ & $x y$ & $x 2-y 2$
\end{tabular}

\begin{tabular}{|l|l|l|l|l|l|}
$\mid 1.178433$ & 1.191016 & 1.068821 & 0.984940 & $1.576790 \mid$ \\
\hline
\end{tabular}

Function: 51 ; Energy: 22787.76064538

Spin labels: $(2 \mathrm{~S}+1)=3.02515$

Symmetry of eigenfunction: $B 1\left(D 2^{*}\right) \quad A 1(C 2 *)$

\begin{tabular}{|l|l|l|l|l|l|l|}
$z 2$ & $y z$ & $x z$ & $x y$ & $x 2-y 2$
\end{tabular}

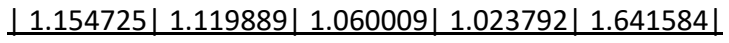

Function: 155 ; Energy: 23534.39173584

Spin labels: $(2 S+1)=1.45559$

Symmetry of eigenfunction: B2(D2*) B1(C2*)

\begin{tabular}{|l|l|l|l|l|} 
z 22 & $y z$ & $x z$ & $x y$ & $x 2-y 2$
\end{tabular}

\begin{tabular}{|l|l|l|l|l|l|}
\hline 1.307245 & 1.293938 & 1.445538 & 0.749401 & 1.203878 \\
\hline
\end{tabular} 
Function: 156 ; Energy: 23657.96502041

Spin labels: $(2 S+1)=1.65363$

Symmetry of eigenfunction: B3(D2*) B1(C2*)

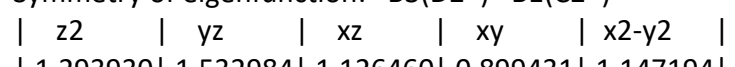

\begin{tabular}{|l|l|l|l|l|l|}
\hline 1.293930 & 1.532984 & 1.126460 & 0.899431 & $1.147194 \mid$ \\
\hline
\end{tabular}

Function: 52 ; Energy: 24231.71786093

Spin labels: $(2 \mathrm{~S}+1)=3.00033$

Symmetry of eigenfunction: $B 1(D 2 *) \quad A 1(C 2 *)$

\begin{tabular}{|l|l|l|l|l|l|l|}
$z 2$ & $y z$ & $x z$ & $x y$ & $x 2-y 2$ & $\mid$
\end{tabular}

\begin{tabular}{|l|l|l|l|l|}
\hline 1.803606 & 1.015922 & 1.004256 & 1.010739 & $1.165476 \mid$ \\
\hline
\end{tabular}

Function: 157 ; Energy: 24252.16687453

Spin labels: $(2 \mathrm{~S}+1)=2.80944$

Symmetry of eigenfunction: B2(D2*) B1(C2*)

\begin{tabular}{|l|l|l|l|l|l}
$z 2$ & $y z$ & $x z$ & $x y$ & $x 2-y 2$
\end{tabular}

\begin{tabular}{|l|l|l|l|l|}
\hline 1.817064 & 1.066907 & 1.033666 & 0.970184 & $1.112179 \mid$ \\
\hline
\end{tabular}

Function: 158 ; Energy: 24463.96461193

Spin labels: $(2 \mathrm{~S}+1)=2.44385$

Symmetry of eigenfunction: $B 3(D 2 *) \quad B 1(C 2 *)$

\begin{tabular}{l|l|l|l|l|l|l|l|l|}
$z 2$ & $y z$ & $x z$ & $x y$ & |
\end{tabular}

\begin{tabular}{|l|l|l|l|l|}
\hline 1.615361 & 1.222273 & 1.057207 & 0.956251 & 1.148908 \\
\hline
\end{tabular}

Function: 159 ; Energy: 24814.95180789

Spin labels: $(2 \mathrm{~S}+1)=2.92610$

Symmetry of eigenfunction: B3(D2*) B1(C2*)

\begin{tabular}{lllllll|l}
$\mathrm{z} 2$ & $\mathrm{yz}$ & $\mathrm{xz}$ & $\mathrm{x} y$ & $\mathrm{x} 2-\mathrm{y} 2$ & |
\end{tabular}

\begin{tabular}{|l|l|l|l|l|l|}
\hline 1.609118 & 1.352555 & 1.185920 & 1.021098 & $0.831308 \mid$ \\
\hline
\end{tabular}

Function: 160 ; Energy: 24815.18257351

Spin labels: $(2 S+1)=2.94040$

Symmetry of eigenfunction: B2(D2*) B1(C2*)

\begin{tabular}{|l|l|l|l|l|l|l|}
$\mathrm{z} 2$ & $\mathrm{yz}$ & $\mathrm{xz}$ & $\mathrm{xy}$ & $\mathrm{x} 2-\mathrm{y} 2$ & |
\end{tabular}

\begin{tabular}{|l|l|l|l|l|l|}
\hline 1.630227 & 1.343092 & 1.142564 & 1.022252 & $0.861865 \mid$ \\
\hline
\end{tabular}

Function: 53 ; Energy: 24819.97681522

Spin labels: $(2 \mathrm{~S}+1)=2.98959$

Symmetry of eigenfunction: $A 1(D 2 *) A 1(C 2 *)$

\begin{tabular}{|l|l|l|l|l|l|l|}
$z 2$ & $y z$ & $x z$ & $x y$ & $x 2-y 2$ & |
\end{tabular} \begin{tabular}{|l|l|l|l|l|l|}
1.623873 & 1.327529 & 1.160781 & 1.037771 & 0.850046 \\
\hline
\end{tabular}

Function: 54 ; Energy: 25126.05794200

Spin labels: $(2 \mathrm{~S}+1)=2.98967$

Symmetry of eigenfunction: $B 1(D 2 *) \quad A 1(C 2 *)$

\begin{tabular}{|l|l|l|l|l|l}
$z 2$ & $y z$ & $x z$ & $x y$ & $x 2-y 2$
\end{tabular}

\begin{tabular}{|l|l|l|l|l|l|}
1 & 1.851016 & 0.949046 & 0.742634 & 0.978685 & 1.478618 \\
\hline
\end{tabular}

Function: 55 ; Energy: 25162.56994332

Spin labels: $(2 \mathrm{~S}+1)=2.99177$

Symmetry of eigenfunction: $A 1\left(D 2^{*}\right) \quad A 1\left(C 2^{*}\right)$

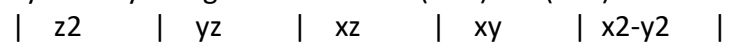

\begin{tabular}{|l|l|l|l|l|l|l|l|l|l|l|}
\hline 1.850574 & 0.967556 & 0.709436 & 0.975212 & $1.497221 \mid$ \\
\hline
\end{tabular}

Function: 56 ; Energy: 25200.11930940

Spin labels: $(2 \mathrm{~S}+1)=2.97062$

Symmetry of eigenfunction: $B 1\left(D 2^{*}\right) \quad A 1(C 2 *)$

\begin{tabular}{|l|l|l|l|l|l|l|}
$\mathrm{z} 2$ & $\mathrm{yz}$ & $\mathrm{xz}$ & $\mathrm{xy}$ & $\mathrm{x} 2-\mathrm{y} 2$ & |
\end{tabular} \begin{tabular}{|l|l|l|l|l|l|}
\hline 1.858582 & 0.785855 & 0.902398 & 0.994014 & $1.459151 \mid$ \\
\hline
\end{tabular}

Function: 161 ; Energy: 25221.68795496

Spin labels: $(2 S+1)=2.99089$

Symmetry of eigenfunction: B3(D2*) B1(C2*)

\begin{tabular}{|l|l|l|l|l|}
$\mathrm{z} 2$ & $\mathrm{yz}$ & $\mathrm{xz}$ & $\mathrm{xy}$ & $\mathrm{x} 2-\mathrm{y} 2$
\end{tabular}

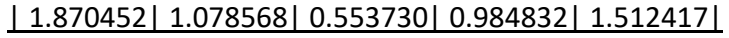


Function: 162 ; Energy: 25267.85130392

Spin labels: $(2 S+1)=2.97794$

Symmetry of eigenfunction: B2(D2*) B1(C2*)

\begin{tabular}{|l|l|l|l|l|l|} 
| z2 & $y z$ & $x z$ & $x y$ & $x 2-y 2$
\end{tabular}

\begin{tabular}{|l|l|l|l|l|}
\hline 1.849354 & 0.686037 & 1.078801 & 0.980051 & 1.405757 \\
\hline
\end{tabular}

Function: 57 ; Energy: 25274.21074849

Spin labels: $(2 \mathrm{~S}+1)=2.98726$

Symmetry of eigenfunction: $A 1(D 2 *) A 1(C 2 *)$

\begin{tabular}{|l|l|l|l|l|l|l|} 
z 22 & $y z$ & $x z$ & $x y$ & $x 2-y 2$
\end{tabular}

\begin{tabular}{|l|l|l|l|l|l|}
1 & 1.858680 & 0.786494 & 0.919135 & 0.990695 & 1.444995 \\
\hline
\end{tabular}

Function: 163 ; Energy: 27018.15927110

Spin labels: $(2 \mathrm{~S}+1)=2.98701$

Symmetry of eigenfunction: $B 2(D 2 *) \quad B 1(C 2 *)$

\begin{tabular}{|l|l|l|l|l|l|}
$\mathrm{z} 2$ & $\mathrm{yz}$ & $\mathrm{xz}$ & $\mathrm{xy}$ & $\mathrm{x} 2-\mathrm{y} 2$
\end{tabular}

\begin{tabular}{|l|l|l|l|l|}
\hline 1.832330 & 0.992175 & 1.022770 & 1.037422 & 1.115303 \\
\hline
\end{tabular}

Function: 164 ; Energy: 27047.62900380

Spin labels: $(2 \mathrm{~S}+1)=2.99483$

Symmetry of eigenfunction: B3(D2*) B1(C2*)

\begin{tabular}{|l|l|l|l|l|l|}
$\mathrm{z} 2$ & $\mathrm{yz}$ & $\mathrm{xz}$ & $\mathrm{xy}$ & $\mathrm{x} 2-\mathrm{y} 2$
\end{tabular}

\begin{tabular}{|l|l|l|l|l|}
\hline 1.831289 & 0.999859 & 1.010022 & 1.037872 & $1.120958 \mid$ \\
\hline
\end{tabular}

Function: 58 ; Energy: 27096.19281766

Spin labels: $(2 \mathrm{~S}+1)=2.99317$

Symmetry of eigenfunction: $B 1\left(D 2^{*}\right) \quad A 1(C 2 *)$

\begin{tabular}{|l|l|l|l|l|l|l|l|}
$z 2$ & $y z$ & $x z$ & $x y$
\end{tabular}

\begin{tabular}{|l|l|l|l|l|}
\hline 1.829205 & 0.996264 & 1.013886 & 1.036658 & 1.123987 \\
\hline
\end{tabular}

Function: 165 ; Energy: 27989.55409186

Spin labels: $(2 \mathrm{~S}+1)=2.97479$

Symmetry of eigenfunction: B3(D2*) B1(C2*)

\begin{tabular}{|l|l|l|l|l|l|l|}
$z 2$ & $y z$ & $x z$ & $x y$ & $x 2-y 2$ & $\mid$
\end{tabular}

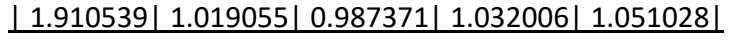

States above $28000 \mathrm{~cm}^{-1}(\lambda=357 \mathrm{~nm})$ are truncated. 


\section{References}

1. Hickey, A. K.; Lee, W.-T.; Chen, C.-H.; Pink, M.; Smith, J. M. Organometallics 2016, 35, 3069.

2. Baker, M. V.; Field, L. D.; Hambley, T. W. Inorg. Chem. 1988, $27,2872$.

3. Prisecaru, I. WMOSS4 Mössbauer Spectral Analysis Software, www.wmoss.org, 2009-2016.

4. Hawrelak, E. J.; Bernskoetter, W. H.; Lobkovsky, E.; Yee, G. T.; Bill, E.; Chirik, P. J. Inorg. Chem. 2005, 44, 3103.

5. Liu, Y.; Luo, L.; Xiao, J.; Wang, L.; Song, Y.; Qu, J.; Luo, Y.; Deng, L. Inorg. Chem. 2015, 54, 4752 .

6. Muller, G.; Sales, J.; Vinaixa, J.; Tejada, J. Inorg. Chim. Acta 1982, 60, 227.

7. Pinkert, D.; Dmeshko, S.; Schax, F.; Braun, B.; Meyer, F.; Limberg, C. Angew. Chem. Int. Ed. 2013, 52, 5155 .

8. Pascualini, M. E.; Di Russo, N. V.; Thuijs, A. E.; Ozarowski, A.; Stoian, S. A.; Abboud, K. A.; Christou, G.; Veige, A. S. Chem. Sci. 2015, 6, 608.

9. Ouyang, Z.; Meng, Y.; Cheng, J.; Xiao, J.; Gao, S.; Deng, L. Organometallics 2016, 35, 1361

10. Gütlich, P.; Bill, E.; Trautwein, A. X. Mössbauer Spectroscopy and Transition Metal Chemistry, Springer: Berlin, 2011; p 441.

11. MacLeod, K. C.; Vinyard, D. J.; Holland, P. L. J. Am. Chem. Soc. 2014, 136, 10226.

12. Dugan, T. R.; Bill, E.; MacLeod, K. C.; Christian, G. J.; Cowley, R. E.; Brennessel, W. W.; Ye, S.; Neese, F.; Holland, P. L. J. Am. Chem. Soc. 2012, 134, 20352.

13. Roy, N.; Sproules, S.; Bill, E.; Weyhermüller, T.; Wieghardt, K. Inorg. Chem. 2008, 47, 10911.

14. Fang, M.; Wilson, S. R.; Suslick, K. S. J. Am. Chem. Soc., 2008, 130, 1134.

15. Rodriguez, M. M.; Bill, E.; Brennessel, W. W.; Holland, P. L. Science 2011, 334, 780. 
16. Dugan, T. R.; Bill, E.; MacLeod, K. C.; Brennessel, W. W.; Holland, P. L. Inorg. Chem. 2014, 53,2370 .

17. Dugan, T. R.; Holland, P. L. J. Organomet. Chem. 2009, 694, 2825

18. Bellows, S. M.; Arnet, N. A.; Gurubasavaraj, P. M. Brennessel, W. W.; Bill, E.; Cundari, T. R.; Holland, P. L. J. Am. Chem. Soc. 2016, 138, 12112.

19. Bain, G. A.; Berry, J. F. J. Chem. Educ. 2008, 85, 532.

20. a) Trofimenko, S. Polyhedron 2004, 23, 197-203. This is part of a special issue on scorpionate ligands, of which other articles are relevant. b) Trofimenko, S. Scorpionates: The coordination chemistry of polypyrazolylborate ligands, London: Imperial College Press, 1999.

21. Liu, Y.; Shi, M.; Deng, L. Organometallics 2014, 33, 5660.

22. Hahn, A. W.; Van Kuiken, B. E.; al Samarai, M.; Atanasov, M.; Weyhermüller, T.; Cui, Y.T.; Miyawaki, J.; Harada, Y.; Nicolaou, A.; DeBeer, S. Inorg. Chem. 2017, 56, 8203.

23. Gruen, D. M.; McBeth, R. L. Pure Appl. Chem. 1963, 6, 23-48. (See p 38).

24. The Racah parameters for $\mathrm{Fe}^{2+}$ free-ion are: $B=897.143 \mathrm{~cm}^{-1}, C=3877.143 \mathrm{~cm}^{-1}(C / B=4.32)$, taken from: Brorson, M.; Schaeffer, C. E. Inorg. Chem. 1988, 27, 2522-2530; (see Table II).

25. Nieto, I.; Bontchev, R. P.; Ozarowski, A.; Smirnov, D.; Krzystek, J.; Telser, J.; Smith, J. M. Inorg. Chim. Acta 2009, 362, 4449.

26. Linn, D. E.; Gibbins, S. G. Inorg. Chem. 1997, 36, 3461.

27. Bau, R.; Ho, D. M.; Gibbins, S. G. J. Am. Chem. Soc. 1981, 103, 4960.

28. Bau, R.; Chiang, M. Y.; Ho, D. M.; Gibbins, S. G.; Emge, T. J.; Koetzle, T. F. Inorg. Chem. 1984, $23,2823$.

29. Scheidt, W. R.; Reed, C. A. Chem. Rev. 1981, 81, 543.

30. Pascualini, M.; Stoian, S. A.; Ozarowski, A.; Abboud, K. A.; Veige, A. S. Inorg. Chem. 2016, $55,5191$. 
31. Xu, S.; Bucinsky, L.; Breza, M.; Krzystek, J.; Chen, C.-H.; Pink, M.; Telser, J.; Smith, J. M. Inorg. Chem. 2017, 56, 14315.

32. Bendix, J., Ligfield. In Comprehensive Coordination Chemistry II, Volume 2: Fundamentals: Physical Methods, Theoretical Analysis, and Case Studies, Lever, A. B. P., Ed. Elsevier: Amsterdam, 2003; Vol. 2, pp 673-676.

33. Neese, F. WIREs Comput. Mol. Sci. 2012, 2, 73.

34. Pantazis, D. A.; Chen, X.-Y.; Landis, C. R.; Neese, F. J. Chem. Theory Comp. 2008, 4, 908.

35. Reger, D. L.; Pascui, A. E.; Smith, M. D.; Jezierska, J.; Ozarowski, A. Inorg. Chem. 2015, 54, 1487.

36. (a) Ginsberg. A. P. J. Am. Chem. Soc. 1980, 102, 111; (b) Noodleman, L. J. Chem. Phys. 1981, 74, 5737; (c) Noodleman, L.; Davidson, E. R. Chem. Phys. 1985, 109, 131.

37. Bencini, A. Gatteschi, D. J. Am. Chem. Soc. 1980, 108, 5763.

38. Soda, T.; Kitagawa, Y.; Onishi T.; Takano Y.; Shigeta, Y.; Nagao, H.; Yoshioka, Y.; Yamaguchi, K. Chem. Phys. Lett. 2000, 319, 223.

39. Neese, F. Coord. Chem. Rev. 2009, 253, 526.

40. (a) Smith, J. M.; Lachicotte, R. J.; Holland, P. L. J. Am. Chem. Soc. 2003, 125, 15752; (b) Vela, J.; Smith, J. M.; Yu, Y.; Ketterer, N. A.; Flaschenriem, C. J.; Lachicotte, R. J.; Holland, P. L. J. Am. Chem. Soc. 2005, 127, 7857; (b) Yu, Y.; Sadique, A. R.; Smith, J. M.; Dugan, T. R.; Cowley, R. E.; Brennessel, W. W.; Flaschenriem, C. J.; Bill, E.; Cundari, T. R.; Holland, P. L. J. Am. Chem. Soc. 2008, 130, 6624; (c) Hein, N. M.; Pick, F. S.; Fryzuk, M. D. Inorg. Chem. 2017, $56,14513$. 